Article

\title{
$\beta$-Cyclodextrin-Based Nanosponges Functionalized with Drugs and Gold Nanoparticles
}

\author{
Isabel Asela ${ }^{1,+}$, Orlando Donoso-González ${ }^{1,2,+} \mathbb{D}$, Nicolás Yutronic ${ }^{1, *}$ and Rodrigo Sierpe ${ }^{1,2,3, * \mathbb{D}}$ \\ 1 Laboratorio de Nanoquímica y Química Supramolecular, Departamento de Química, Facultad de Ciencias, \\ Universidad de Chile, Las Palmeras 3425, Nuñoa, 7800003 Santiago, Chile; i.asela.m@gmail.com (I.A.); \\ orlando.donoso@ug.uchile.cl (O.D.-G.) \\ 2 Laboratorio de Nanobiotecnología y Nanotoxicología, Departamento de Química Farmacológica y \\ Toxicológica, Facultad de Ciencias Químicas y Farmacéuticas, Universidad de Chile, Santos Dumont 964, \\ Independencia, 8380000 Santiago, Chile \\ 3 Laboratorio de Biosensores, Departamento de Química Farmacológica y Toxicológica, Facultad de Ciencias \\ Químicas y Farmacéuticas, Universidad de Chile, Santos Dumont 964, Independencia, \\ 8380000 Santiago, Chile \\ * Correspondence: nyutroni@uchile.cl (N.Y.); rsierpe@ciq.uchile.cl (R.S.); \\ Tel.: +562-29787255 (N.Y.); +562-29782885 (R.S.) \\ + Main Authors.
}

check for updates

Citation: Asela, I.; Donoso-González, O.; Yutronic, N.; Sierpe, R.

$\beta$-Cyclodextrin-Based Nanosponges Functionalized with Drugs and Gold Nanoparticles. Pharmaceutics 2021, 13 , 513. https://doi.org/10.3390/ pharmaceutics13040513

Academic Editors: Francisco José Ostos, José Antonio Lebrón and Pilar López-Cornejo

Received: 17 February 2021

Accepted: 4 April 2021

Published: 8 April 2021

Publisher's Note: MDPI stays neutral with regard to jurisdictional claims in published maps and institutional affiliations.

Copyright: (c) 2021 by the authors. Licensee MDPI, Basel, Switzerland. This article is an open access article distributed under the terms and conditions of the Creative Commons Attribution (CC BY) license (https:/ / creativecommons.org/licenses/by/ $4.0 /)$.

\begin{abstract}
Drugs are widely used as therapeutic agents; however, they may present some limitations. To overcome some of the therapeutic disadvantages of drugs, the use of $\beta$-cyclodextrin-based nanosponges $(\beta C D N S)$ constitutes a promising strategy. $\beta C D N S$ are matrices that contain multiple hydrophobic cavities, increasing the loading capacity, association, and stability of the included drugs. On the other hand, gold nanoparticles (AuNPs) are also used as therapeutic and diagnostic agents due to their unique properties and high chemical reactivity. In this work, we developed a new nanomaterial based on $\beta C D N S$ and two therapeutic agents, drugs and AuNPs. First, the drugs phenylethylamine (PhEA) and 2-amino-4-(4-chlorophenyl)-thiazole (AT) were loaded on $\beta C D N S$. Later, the $\beta C D N S-$ drug supramolecular complexes were functionalized with AuNPs, forming the $\beta C D N S-P h E A-A u N P$ and $\beta C D N S-A T-A u N P$ systems. The success of the formation of $\beta C D N S$ and the loading of PhEA, AT, and AuNPs was demonstrated using different characterization techniques. The loading capacities of PhEA and AT in $\beta C D N S$ were $90 \%$ and $150 \%$, respectively, which is eight times higher than that with native $\beta C D$. The functional groups $\mathrm{SH}$ and $\mathrm{NH}_{2}$ of the drugs remained exposed and allowed the stabilization of the AuNPs, $85 \%$ of which were immobilized. These unique systems can be versatile materials with an efficient loading capacity for potential applications in the transport of therapeutic agents.
\end{abstract}

Keywords: $\beta$-cyclodextrin-based nanosponge; phenylethylamine; 2-amino-4-(4-chlorophenyl)thiazole (AT); gold nanoparticles; carrier of therapeutic agents

\section{Introduction}

$\beta$-cyclodextrin $(\beta C D)$ is a cyclic oligosaccharide approved by the FDA (Food and Drug Administration) that has been widely used as a pharmaceutical excipient in food products, textiles, cosmetics, and medical products [1]. In modern drug delivery investigations, $\beta C D$ has been used as a host molecule for the preparation of drug carrier systems in diverse forms, such as vesicles, hydrogels, micelles, metal-organic systems, and nanoparticles [2-6]. Structural modifications of native $\beta C D$ have been shown to increase its inclusion capacity and solubility and have allowed bioapplications of a large number of guest biomolecules [7-9]. An innovative modification to $\beta C D$ recently studied was the synthesis of a polymeric crosslinked network, forming a highly porous and branched matrix of nanometric dimensions called the $\beta$-cyclodextrin-based nanosponge ( $\beta C D N S)[10,11]$. This nanostructure contains multiple lipophilic cavities and carbonate bridges, leading to a network of hydrophilic 
channels [12], which allows $\beta C D N S$ to serve as a polymeric conjugate, increasing the loading capacity, association, and stability of the included drugs [7,13-19]. Notably, a high loading capacity is a characteristic feature of $\beta C D N S$ since they can interact with different molecules of suitable dimensions, using either the cavities of $\beta C D$ or the multiple pores generated in the crosslinking [7,11,12]. Due to the above, studies on $\beta C D N S$ applied to drug administration have been reported.

Drugs are some of the most widely used therapeutic agents; however, they may present some limitations, such as early instability, poor aqueous solubility, and low bioavailability. Therefore, strategies for the inclusion of drugs in matrices of native or modified $\beta C D$ have been an excellent alternative for solving these disadvantages. In this work, the loading of the drugs phenylethylamine (PhEA) and 2-amino-4-(4-chlorophenyl)-thiazole (AT) on $\beta C D N S$ was studied, which led to formation of two new systems: $\beta C D N S-P h E A$ and $\beta C D N S-A T$. PhEA is a psychoactive stimulant that is used as an antidepressant without inducing tolerance; however, it is rapidly metabolized in organisms by the MAO-B enzyme, making it difficult to reach the site of action $[20,21]$. AT is a thiazole derivative that is currently used as an antimicrobial and anti-inflammatory agent but is rapidly degraded and has a poor aqueous solubility [22-24]. Our group previously studied complex formation between native $\beta C D$ and these drugs. An increase was reported in the aqueous solubility and stability of PhEA over time due to its inclusion; in addition, the drug was released from the $\beta C D-P h E A$ complex using laser irradiation and gold nanoparticles (AuNPs) present in the medium [25]. The inclusion of AT in $\beta C D$ increased its aqueous solubility, allowing the application of higher doses in in vitro studies of permeability and antibacterial activity. Finally, it was demonstrated that the $\beta C D-A T$ complex maintained its antibacterial activity against six strains of clinical relevance [26]. In this sense, the incorporation of $\beta C D N S$ could show novel results, increasing the loading capacity or solubility, among other advantages $[7,10,11,16]$. Notably, AuNPs could also be added as a remarkable second therapeutic agent.

AuNPs have been widely employed in nanobiotechnology due to their unique properties, which allow them to be incorporated into new nanomaterials [27]. The main characteristics of AuNPs include their optoelectronic properties, as surface plasmon resonance (SPR), which are related to their shape, size, and large surface-to-volume ratio; besides its excellent biocompatibility and low toxicity [28]. The chemical reactivity of the surface atoms of AuNPs allows their functionalization and assembly with various chemical species, enabling their application in chemical and biological sensing, imaging, therapeutics, detection and diagnostics, biolabeling, and drug delivery [29-35]. Notably, AuNPs have been used as therapeutic and diagnostic agents, even in hard-to-reach places, such as the brain, since they can cross the blood-brain barrier [36-40]. Due to their photothermal properties, AuNPs can release compounds that are attached or close to its surface, such as drugs, at specific sites of action in a controlled manner due to the generation of thermal energy when excited by a laser specifically tuned to the SPR frequency [25,41,42]. Furthermore, AuNPs can accumulate passively in sites with an immature vasculature and with extensive fenestrations, such as tumor tissues, or in injured sites where an immune response develops. This is called the enhanced permeability and retention effect (EPR effect) [43-45]. It has been shown that the EPR effect combined with a longer blood circulation time of some types of nanoparticles can increase drug concentrations in tumors by 10 to 100 times compared to the use of free drugs [46]. In recent years, a series of complexes based on $\beta C D$ have allowed the stabilization of AuNPs, building systems with promising applications in biological and chemical areas $[25,26,47-53]$. Therefore, if properly designed, $\beta C D N S$ loaded with drugs and AuNPs could be used as new systems with biomedical applications, acting synergistically in nanotherapy.

In this work, we propose the development of a new system based on $\beta C D N S$ for the transport of two therapeutic agents, drugs and AuNPs. For this, inclusions of PhEA and AT were studied separately. Later, the complexes were functionalized with AuNPs, forming the $\beta C D N S-P h E A-A u N P$ and $\beta C D N S-A T-A u N P$ systems. We believe that these unique 
systems, based on $\beta C D N S$, drugs, and AuNPs, can be versatile materials with potential applications in the therapy and diagnosis of diseases.

\section{Materials and Methods}

\subsection{Material}

Anhydrous $\beta C D\left(\mathrm{C}_{42} \mathrm{H}_{70} \mathrm{O}_{35}\right) \geq 97 \%, 1134.98 \mathrm{~g} / \mathrm{mol}$; diphenylcarbonate (DPC, $\left.\left.\mathrm{C}_{6} \mathrm{H}_{5} \mathrm{O}\right)_{2} \mathrm{CO}\right) 99 \%, 214.22 \mathrm{~g} / \mathrm{mol}$; PhEA $\left(\mathrm{C}_{8} \mathrm{H}_{11} \mathrm{~N}\right) \geq 99.5 \%, 121.18 \mathrm{~g} / \mathrm{mol}$, density $(\delta)$ : $0.962 \mathrm{~g} / \mathrm{mL}$; AT $\left(\mathrm{C}_{9} \mathrm{H}_{7} \mathrm{ClN}_{2} \mathrm{~S}\right) \geq 98 \%, 210.68 \mathrm{~g} / \mathrm{mol}$; sodium hydroxide $(\mathrm{NaOH}) \geq 97 \%$, $40.00 \mathrm{~g} / \mathrm{mol}$; tetrachloroauric acid $\left(\mathrm{HAuCl}_{4}\right) \geq 99.9 \%, 393.83 \mathrm{~g} / \mathrm{mol}$; and sodium citrate $\left(\mathrm{Na}_{3} \mathrm{C}_{6} \mathrm{H}_{5} \mathrm{O}_{7}\right) \geq 99 \%, 294.10 \mathrm{~g} / \mathrm{mol}$ were provided by Merck (Merck, Darmstadt, Germany). Ultrapure water $\left(18 \mathrm{MWcm}^{-1}\right)$ was obtained from a Milli-Q water system (Synergy UV equipment, Merck, Darmstadt, Germany).

\subsection{Synthesis of $\beta$-Cyclodextrin Nanosponges}

For $\beta C D N S$ synthesis, anhydrous $\beta C D$ and DPC were used as precursors. Synthesis was carried out by adapting Patel's protocol [54]. $\beta C D(0.189 \mathrm{~g})$ and $0.143 \mathrm{~g}$ of DPC were mixed in solid state at a 1:4 molar ratio $\beta C D$ :DPC. A round-bottom flask with the mixture was heated inside an oil bath on a heating plate, with constant stirring for $5 \mathrm{~h}$ at $100{ }^{\circ} \mathrm{C}$, observing its melting. The solid mixture obtained was ground in a mortar, washed with distilled water, and filtered under vacuum. The product was washed in a Soxhlet apparatus with acetone for $24 \mathrm{~h}$, to remove phenol by-product. Later, it was moistened with water and dried for $2 \mathrm{~h}$ in a vacuum system using a Buchner funnel connected to a Kitasato flask to remove trace $\beta C D$. Finally, the product was dried for $72 \mathrm{~h}$ at $65^{\circ} \mathrm{C}$ and stored.

\section{3. $\beta$-Cyclodextrin Nanosponges Loading with Drugs}

To load $\beta C D N S$ with PhEA and AT, the saturated solutions method [55] was used with minor modifications. $\beta C D N S$ were dispersed in a $\mathrm{NaOH} 0.1 \mathrm{M}$ solution at room temperature, while the drugs were dissolved in ethanol. The solutions were mixed under constant agitation for $15 \mathrm{~min}$ and then left without agitation for $24 \mathrm{~h}$. The resulting solution was centrifuged, and the supernatant was lyophilized and reserved [56,57]. The loading capacity of the $\beta C D N S-P h E A$ and $\beta C D N S-A T$ systems was calculated from the weights of $\beta C D$ and drugs obtained using Equation (1) [58].

$$
\text { Loading capacity }=\frac{\text { Weight of drug in } \beta C D N S}{\text { Weight of } \beta C D \text { in } \beta C D N S} \times 100
$$

\subsection{Association Constant, $K_{a}$}

For both drugs, studies were performed following the Higuchi and Connors method [59]. First, known concentrations (C) of each drug were measured by UV-Vis. From the $A_{\max }$ vs. $C$ graph, the slope corresponded to the $\varepsilon$ of each drug. Then, the $\beta C D N S$ concentration versus the loaded drug concentration (calculated by Beer-Lambert law) was plotted. The value of the slope of the graphs related the amount of $\beta C D N S$ added to the amount of solubilized drug, indicating the degree of solubilization. Degree of solubilization was used to calculate the association constant $\left(\mathrm{K}_{\mathrm{a}}\right)$ and complexation efficiency of each system using Equations (2) and (3), respectively.

$$
\begin{gathered}
\qquad \mathrm{K}_{\mathrm{a}(1: 1)}=\frac{\text { Degree of solubilization }}{\left[\mathrm{C}_{\mathrm{o}}\right](1-\text { Degree of solubilization })} \\
\text { Complexation efficiency }=\mathrm{K}_{\mathrm{a}(1: 1)}\left[\mathrm{C}_{\mathrm{o}}\right]=\frac{\text { Degree of solubilization }}{(1-\text { Degree of solubilization })}
\end{gathered}
$$

$\left[C_{\mathrm{o}}\right]$ corresponds to the concentration of the free drug in the absence of $\beta C D N S$. 


\subsection{Synthesis of Gold Nanoparticles and Their Immobilization on $\beta$-Cyclodextrin} Nanosponges-Drug Systems

Synthesis of AuNPs was performed using the Turkevich method [60]. A reflux system on a round-bottom flask (with three necks) was mounted by placing a thermometer, a condenser, and a rubber stopper on each neck. Here, $0.474 \mathrm{~mL}$ of $\mathrm{HAuCl}_{4}$ was added with $18 \mathrm{~mL}$ of water. Sodium citrate $(22.8 \mathrm{mg})$ was dissolved in $2.0 \mathrm{~mL}$ of water and heated at $60{ }^{\circ} \mathrm{C}$ for approximately $5 \mathrm{~min}$. When aqueous solution of $\mathrm{HAuCl}_{4}$ was refluxed and the gas-liquid equilibrium stabilized at a temperature of $186{ }^{\circ} \mathrm{C}$, the citrate solution (at $60{ }^{\circ} \mathrm{C}$ ) was added through the neck with the stopper. The reflux was continued under constant agitation $(6 \times g)$ for $30 \mathrm{~min}$ until a deep red solution was obtained. Later, the solution was cooled slowly to room temperature. The obtained AuNPs were filtered, diluted, set to $\mathrm{pH}$ 8.8 using an $\mathrm{NaOH}$ solution, and stored at $4{ }^{\circ} \mathrm{C}$.

Immobilization was carried out via solubilization of the $\beta C D N S-$ drug supramolecular complexes in an alkaline environment of AuNPs, setting the $\mathrm{pH}$ to 8.8 using $\mathrm{NaOH}$. These mixtures formed homogeneous colloidal solutions that were centrifuged to decant only the $\beta C D N S-d r u g$ systems interacting with AuNPs. Once the systems $\beta C D N S-d r u g-A u N P$ were separated from the supernatant, they were resuspended in a new aqueous solution, forming the systems $\beta C D N S-A T-A u N P$ and $\beta C D N S-P h E A-A u N P$. The concentration of AuNPs was calculated using UV-Vis spectroscopy. The molar extinction coefficient was obtained from the literature [61,62], and it was applied together with the Beer-Lambert equation.

\subsection{Analysis by Nuclear Magnetic Resonance of Protons, ${ }^{1} \mathrm{H}-\mathrm{NMR}$}

All the samples were dissolved in deuterated dimethylsulfoxide (DMSO)- $\mathrm{d}_{6}$.

2.7. Preparation of Samples for Studies by Scanning and Transmission Electron Microscopy, SEM and TEM

For SEM studies, the $\beta C D$ and $\beta C D N S$ samples were prepared directly depositing the solid material onto carbon tape, then a gold coating was applied using magneton sputtering (pressure $0.5 \mathrm{mbar}$, Ar atmosphere, current $25 \mathrm{~mA}$ over $15 \mathrm{~s}$ ). $\beta C D N S-d r u g-A u N P$ samples were prepared by dropping aliquots on carbon tape, allowing them to dry overnight. The AuNPs immobilized on $\beta$ CDNS-drug systems allowed the conductivity of these samples.

For TEM studies, the $\beta C D$ and $\beta C D N S$ samples were dissolved in ethanol $(20 \% v / v)$, then mixed, sonicated, and dripped onto a copper grid with a continuous Formvar film. The $\beta C D N S-$ drug samples were dissolved in ethanol $(20 \% v / v)$, then mixed, sonicated, and dripped onto a holey carbon grid. Finally, all these samples were stained with phosphotungstic acid. The AuNPs samples were deposited directly on the grid with a continuous Formvar film.

\subsection{Preparation of the Samples for Studies by Dynamic Light Scattering (DLS) and $\zeta$ Potential}

$\beta C D N S$ and $\beta C D N S-d r u g s$ were redispersed to measurements. To determine the size distribution of the samples, the results were retrieved from the intensity distribution values using the cumulant method. The measurement conditions were set for organic $\beta C D$-based samples (refraction index: 1.49 and k: 0).

AuNPs and AuNPs with $\beta C D N S-$ drug were diluted $10 \times$ for measurements. Sonication and filtration were performed through a $0.45 \mu \mathrm{m}$ filter. To determine the size distribution of AuNPs on the samples, the results were retrieved from the intensity distribution values using the cumulant method. On the other hand, the Smoluchowski approximation was used to calculate the $\zeta$ potentials from the measured electrophoretic mobility. The measurement conditions were set for colloidal gold samples (refraction index: 1.33 and $\mathrm{k:} 0.20)$. 


\subsection{Equipment Used for Characterization of the Samples}

\subsubsection{Nuclear Magnetic Resonance of Protons, ${ }^{1} \mathrm{H}-\mathrm{NMR}$}

${ }^{1} \mathrm{H}-\mathrm{NMR}$ characterizations of the $\beta C D N S$, PhEA, AT, and $\beta C D N S-$ drug samples were performed in a Bruker Advance $400 \mathrm{MHz}$ instrument (Bruker, Billerica, MA, USA) at $30{ }^{\circ} \mathrm{C}$ using TMS as an internal reference. The MestreNova program was used for data processing.

\subsubsection{Infrared Spectroscopy, IR}

The analyses were performed on a Jasco FT/IR-4600 instrument (Jasco, Easton, PA, USA). Spectral resolution: $1 \mathrm{~cm}^{-1}$, number of scans: $4 . \mathrm{CO}_{2}$ and $\mathrm{H}_{2} \mathrm{O}$ correction through the software of the equipment was made. Baseline correction of $\mathrm{KBr}$ was performed.

\subsubsection{Thermogravimetric Analysis, TGA}

Analyses were performed on Perkin-Elmer model 4000 equipment (Perkin-Elmer, Waltham, MA, USA) over a temperature range from $0^{\circ} \mathrm{C}$ to $800^{\circ} \mathrm{C}$ with a rate of $10^{\circ} \mathrm{C} / \mathrm{min}$ under an air atmosphere with a flow of $20 \mathrm{~mL} / \mathrm{min}$.

\subsubsection{Scanning and Transmission Electron Microscopy, SEM and TEM}

For both characterizations, Inspect F50 HR-SEM instrument (Fei Company, Hillsboro, OR, USA) was used. For the scanning electron microscopy (SEM) images, an EverhartThornley detector was used, while for the transmission electron microscopy (TEM) images, the detector was scanning transmission electron microscope (STEM). An acceleration voltage of $10.0 \mathrm{kV}$, pressure of $9.71 \times 10^{-8} \mathrm{~Pa}$, and observation magnitudes of $16,000 \times$ and $100,000 \times$ were used.

\subsubsection{UV-Visible Spectrophotometry}

A Shimadzu UV-2450 instrument (Shimadzu, Kyoto, Japan) was employed to obtain the absorbance spectra. Measurements were made in $1.0 \mathrm{~cm}$ diameter quartz cuvettes between 200 and $800 \mathrm{~nm}$ using water at $\mathrm{pH} 8.8$ as the reference. The UVProve program, version 1.10 , was used for data processing.

\subsubsection{Dynamic Light Scattering (DLS) and $\zeta$ Potential}

The samples were measured on a Malvern Zetasizer Nano ZS instrument (Malvern, Malvern, UK).

\subsubsection{Lyophilization of the Samples}

BenchTop Pro, Omnitronic team equipment, SP Scientific (Omnitronic team, Gardiner, NY, USA) was used.

For data processing and graphic design, OriginPro 8.0 software (OriginLab, Northampton, MA, USA) was used.

\subsubsection{Metallization of the Samples}

PELCO SC-6 magnetron sputtering (PELCO, Fresno, CA, USA) was used. A gold foil was placed inside the vacuum chamber at $0.5 \mathrm{mbar}$, under inert atmosphere of argon. To begin the process, a current of $25 \mathrm{~mA}$ was used over $15 \mathrm{~s}$ to ionize the gas, hitting the metal foil and releasing $\mathrm{Au}$ atoms. These $\mathrm{Au}$ atoms were deposited over the $\beta C D$ and $\beta C D N S$ systems.

\section{Results and Discussion}

\subsection{Synthesis and Characterization of $\beta$-Cyclodextrin-Based Nanosponges}

Different synthesis routes have been reported for $\beta C D N S$ formation, and they use ultrasonic baths; heating plates; solvents, such as ethanol or acetone for the washing stages; and even different molar ratios of $\beta C D$ and DPC $[7,10]$. For this reason, different methodologies were evaluated to optimize the synthesis of $\beta C D N S$, eliminate byproducts, 
and increase yield. For the ultrasonic bath (A) and heating plate (B) methods, the use of acetone and a 1:4 molar ratio showed yields greater than 60\%, as shown in Figure A1 (Appendix A). Considering the reproducibility of the synthesis and the lower amount of generated byproducts exhibited by method B relative to method A, method B with a heating plate was selected.

$\beta C D N S$ formation was confirmed using ${ }^{1} \mathrm{H}-\mathrm{NMR}$. The technique allowed us to compare the chemical shifts of the signals for $\beta C D$ protons in $\beta C D N S$ and in native $\beta C D$. Figure 1 shows the spectra of (A) $\beta C D$, (B) DPC, and (C) $\beta C D N S$ with a scheme showing the proton assignments for $\beta C D$ and DPC. Table 1 shows the proton assignment for $\beta C D$ and their respective chemical shifts and integrations in the ${ }^{1} \mathrm{H}-\mathrm{NMR}$ spectra. The shifts of the signals are due to the change in the chemical environment of the $\beta C D$ matrices when they are linked to form $\beta C D N S$. Notably, the greatest changes were observed in the integration delta $\left(\Delta \int\right)$ of the hydroxyl groups, because they react with DPC to form linkers between $\beta C D$ matrices, strongly suggesting $\beta C D N S$ formation.
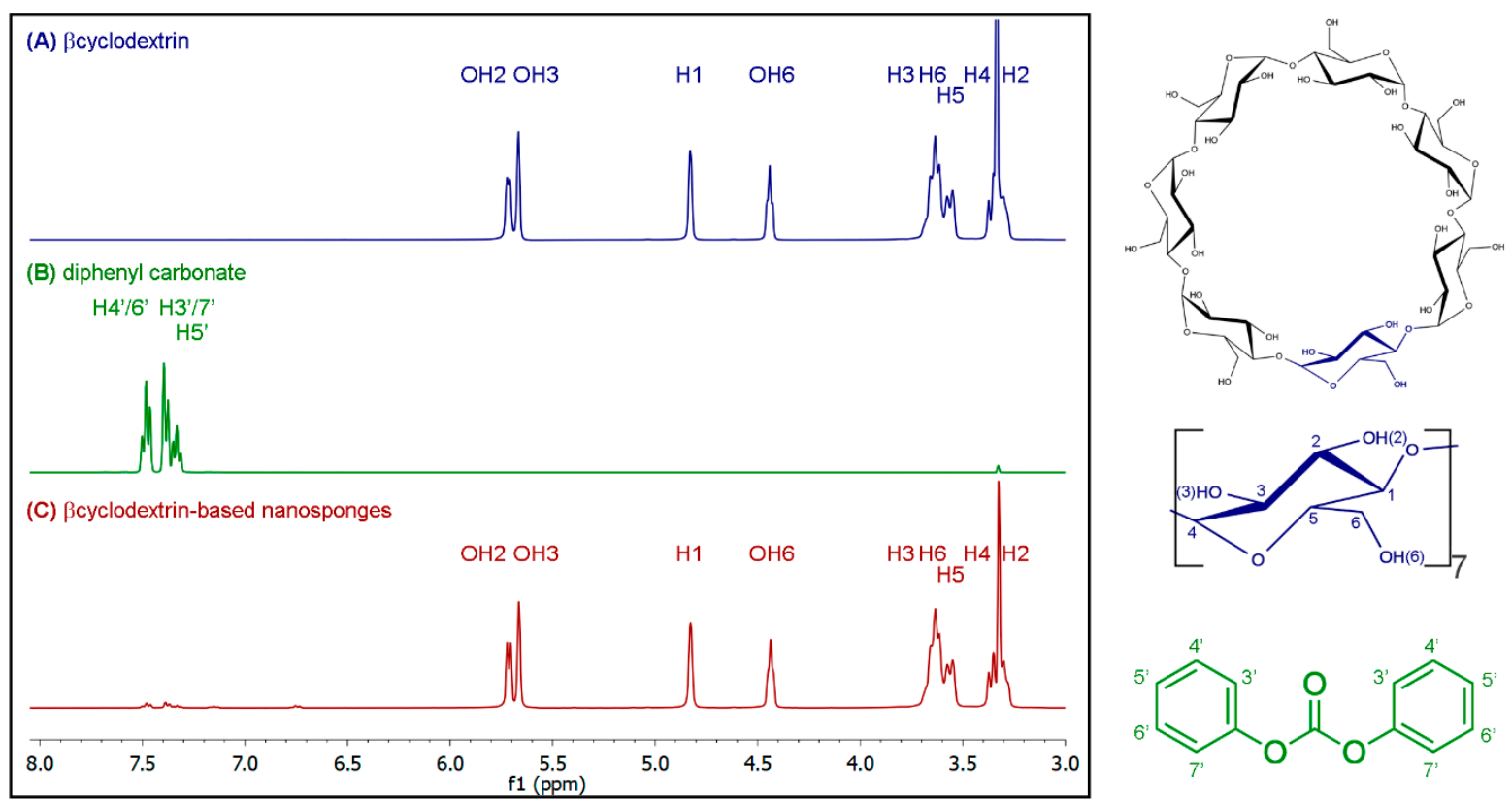

Figure 1. ${ }^{1} \mathrm{H}$-NMR spectra of (A) native $\beta$-cyclodextrin $(\beta C D)$, (B) diphenylcarbonate (DPC), and (C) $\beta$-cyclodextrin-based nanosponge ( $\beta C D N S)$ synthesized (left) together with the molecular structures and the assignments of the protons of $\beta C D$ and DPC (right).

Table 1. Proton assignments, ${ }^{1} \mathrm{H}-\mathrm{NMR}$ chemical shifts, and integrations of the $\beta$-cyclodextrin $(\beta C D)$ and $\beta$-cyclodextrinbased nanosponge ( $\beta C D N S)$ signals.

\begin{tabular}{|c|c|c|c|c|c|c|}
\hline Protons & $\delta \beta C D(p p m)$ & $\begin{array}{c}\delta \beta C D N S \\
(\mathrm{ppm})\end{array}$ & $|\Delta \delta|(p p m)$ & $\begin{array}{c}\beta C D \\
\text { Integration }\left(\int\right)\end{array}$ & $\begin{array}{c}\beta C D N S \\
\text { Integration }\left(\int\right)\end{array}$ & $\mid \Delta \int \mathrm{I}$ \\
\hline $\mathrm{H} 1$ & 4.825 & 4.827 & 0.002 & 7.00 & 7.00 & 0 \\
\hline $\mathrm{H} 2$ & 3.311 & 3.301 & 0.010 & 6.99 & 6.98 & 0.01 \\
\hline H3 & 3.669 & 3.655 & 0.014 & 6.99 & 6.98 & 0.01 \\
\hline $\mathrm{H} 4$ & 3.370 & 3.361 & 0.009 & 7.14 & 7.15 & 0.01 \\
\hline H5 & 3.566 & 3.562 & 0.004 & 7.04 & 7.04 & 0 \\
\hline H6 & 3.621 & 3.624 & 0.003 & 13.83 & 13.84 & 0.01 \\
\hline $\mathrm{OH} 2$ & 5.706 & 5.714 & 0.008 & 7.01 & 6.68 & 0.33 \\
\hline $\mathrm{OH} 3$ & 5.661 & 5.665 & 0.004 & 7.02 & 6.57 & 0.45 \\
\hline OH6 & 4.435 & 4.437 & 0.002 & 7.15 & 6.43 & 0.72 \\
\hline
\end{tabular}

$\beta C D N S$ formation was also characterized using IR vibrational spectroscopy. Commonly, this study focuses on comparing the signals of native $\beta C D$ and $\beta C D$ forming 
nanosponges and recognizing the vibration signal of the carbonyl group, which is an indicator of $\beta C D$ crosslinking. Figure $2 A$ shows the IR spectra of $(A) \beta C D,(B) D P C$, and $(C)$ $\beta C D N S$. Characteristic peaks of $\beta C D$ are observed at $3363 \mathrm{~cm}^{-1}(\mathrm{O}-\mathrm{H}$ alcohol stretching), $2924 \mathrm{~cm}^{-1}$ (C-H stretching), $1417 \mathrm{~cm}^{-1}, 1368 \mathrm{~cm}^{-1}, 1157 \mathrm{~cm}^{-1}\left(\mathrm{O}-\mathrm{H}\right.$ bending), $1080 \mathrm{~cm}^{-1}$, and $1029 \mathrm{~cm}^{-1}$ (C-O stretching). These data are consistent with literature data [63-65]. For $\beta C D N S$, the characteristic peaks are located mostly in the same regions observed for $\beta C D$, but with shifts or variations in intensity due to changes in the chemical environment. These were observed at $3366 \mathrm{~cm}^{-1}$ (O-H alcohol stretching), $2928 \mathrm{~cm}^{-1}$ (C-H stretching), $1645 \mathrm{~cm}^{-1}$ (C=O stretching), 1367, 1234, and $1155 \mathrm{~cm}^{-1}\left(\mathrm{O}-\mathrm{H}\right.$ bending), and $1079 \mathrm{~cm}^{-1}$ and $1030 \mathrm{~cm}^{-1}$ (C-O stretching). Notably, the appearance of peaks at 1783, 1715, and $1235 \mathrm{~cm}^{-1}$ derived from signals present in DPC confirm the crosslinking of $\beta C D$ forming nanosponges. The peak at $1760 \mathrm{~cm}^{-1}(\mathrm{C}=\mathrm{O}$ stretching) of DPC is masked by a peak in the $\beta C D N S$ spectrum.

Thermogravimetry was performed to analyze and confirm the formation of $\beta C D N S$, differentiating it from its precursors through changes in their thermal decomposition, as is typically observed in the synthesis of polymeric materials [66]. Figure 2B shows thermograms of $(A) \beta C D,(B) D P C$, and (C) $\beta C D N S$. The loss of hydration water was observed in the first decomposition at temperatures up to $100{ }^{\circ} \mathrm{C}$, with the percentage of mass loss being $11.5 \%$ for $\beta C D$ and $2.7 \%$ for $\beta C D N S$ of the total mass samples. Decomposition of $100 \%$ of the mass of DPC was observed in the range 130 to $250{ }^{\circ} \mathrm{C}$. A second range of decomposition in $\beta C D$ was observed between 300 and $350{ }^{\circ} \mathrm{C}$, corresponding to a loss of $71 \%$ of the sample mass. For $\beta C D N S$, this second range was between 210 and $350{ }^{\circ} \mathrm{C}$, consuming $70 \%$ of the total mass. The decrease in the temperature at the beginning of thermal degradation suggests that DPC, a crosslinker molecule, binds to the primary $\mathrm{OH}$ groups of $\beta C D s$, forming the nanopolymer through carbonyl groups. Changes in the peaks of the TGA curves (see Figure A2 in Appendix A) from $337{ }^{\circ} \mathrm{C}(\beta C D)$ to $327(\beta C D N S)$ are typically observed in the formation of polymeric materials due to changes in chemical structure [67-69]. Finally, the oxidation interval for $\beta C D$ ranged from 350 to $700{ }^{\circ} \mathrm{C}$, encompassing $17.5 \%$ of the mass. However, $\beta C D N S$ oxidation ranges from 350 to $580{ }^{\circ} \mathrm{C}$, encompassing $27.3 \%$ of the mass. This also suggests modifications in the reactive structure of the polymer relative to native $\beta C D$.

To explain the change in the beginning of the range of thermal degradation for $\beta C D N S$, the average between the beginning temperatures for $\beta C D$ and DPC, which were 300 and $130{ }^{\circ} \mathrm{C}$, respectively, was evaluated. The calculated average temperature was $215^{\circ} \mathrm{C}$, which coincided with the value of the beginning of thermal degradation observed in the $\beta C D N S$ thermogram, fulfilling the "eutectic mixture" criterion [70]. In addition, the high value of the degradation interval for $\beta C D N S$ supports its thermal stability.

To obtain information on the morphology and size of $\beta C D N S$, the material was characterized using electron microscopy techniques and DLS. Figure 3 shows micrographs obtained by FE-SEM of native $\beta C D$ (Figure 3A) and $\beta C D N S$ (Figure 3B), directly revealing the morphological differences between both. $\beta C D$ has irregular crystalline structures, while $\beta C D N S$ has a characteristic porous appearance. TEM images were obtained to determine the average diameter of $\beta C D N S$, which were previously dispersed by sonication. Figure $3 C, D$ shows the $\beta C D N S$ and the resulting histogram, respectively. The average diameter, obtained from the count of more than 450 nanoparticles seen in various TEM images, was $146 \pm 54 \mathrm{~nm}$ (see more images in Figure A3 in Appendix A). The staining of the $\beta C D N S$ sample revealed some $\beta C D$ crystals, which was verified by obtaining TEM images of native $\beta C D$ with the same dispersion and staining protocol described for $\beta C D N S$ (see Figure A3 in Appendix A). In addition, a hydrodynamic diameter of $133.9 \pm 66.9 \mathrm{~nm}$ was found for $\beta C D N S$ using DLS. These size data are concordant and strongly suggest the nanometric dimensions of the system studied (see more details in Appendix $C$ ). 
(A)

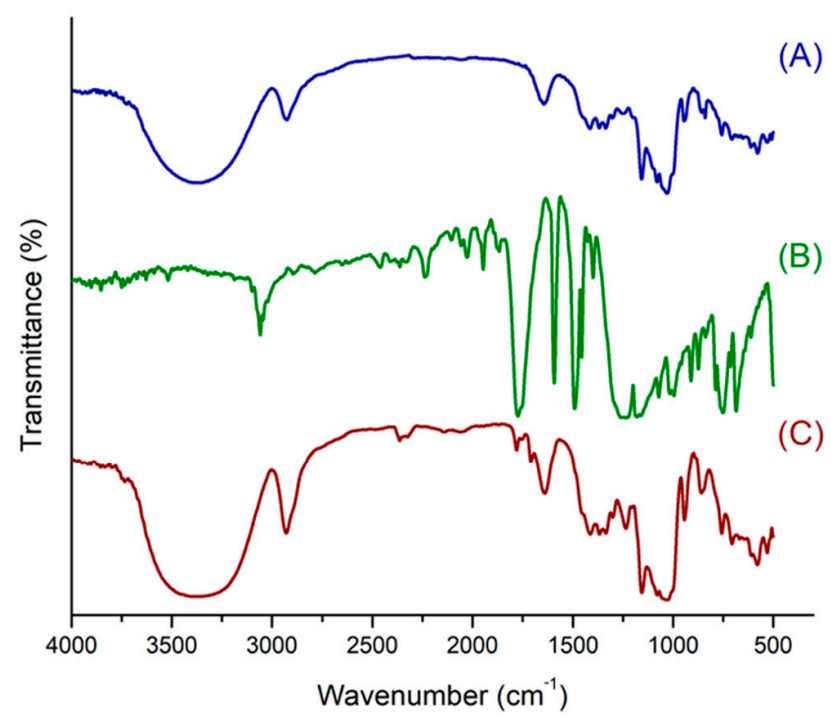

(B)

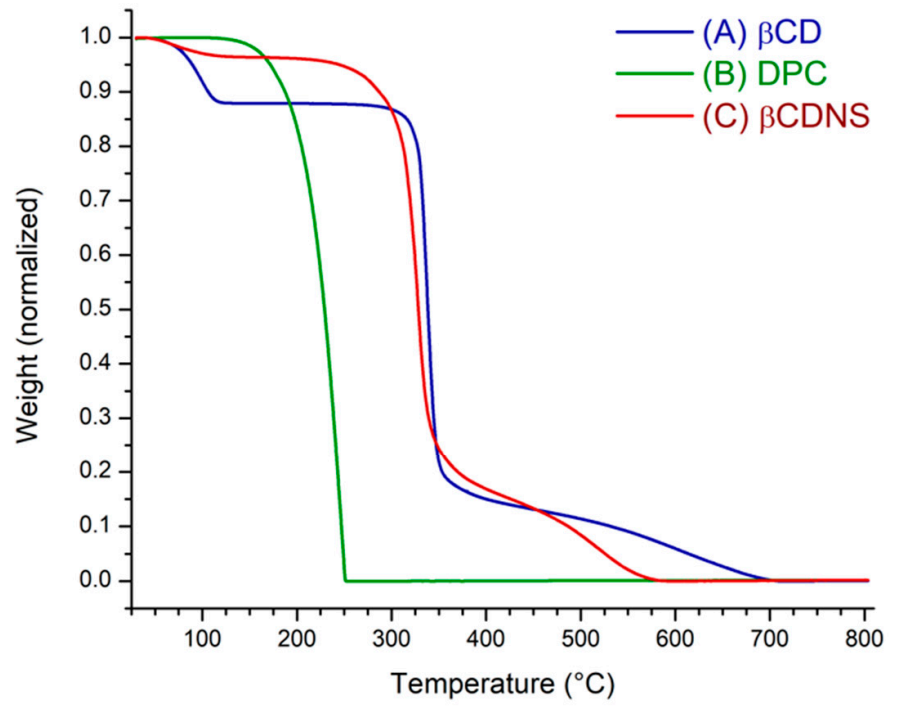

Figure 2. (A) FT-IR spectra of (A) $\beta C D$, (B) DPC, and (C) $\beta C D N S$; (B) normalized thermograms of (A) $\beta C D$, (B) DPC, and (C) $\beta C D N S$.
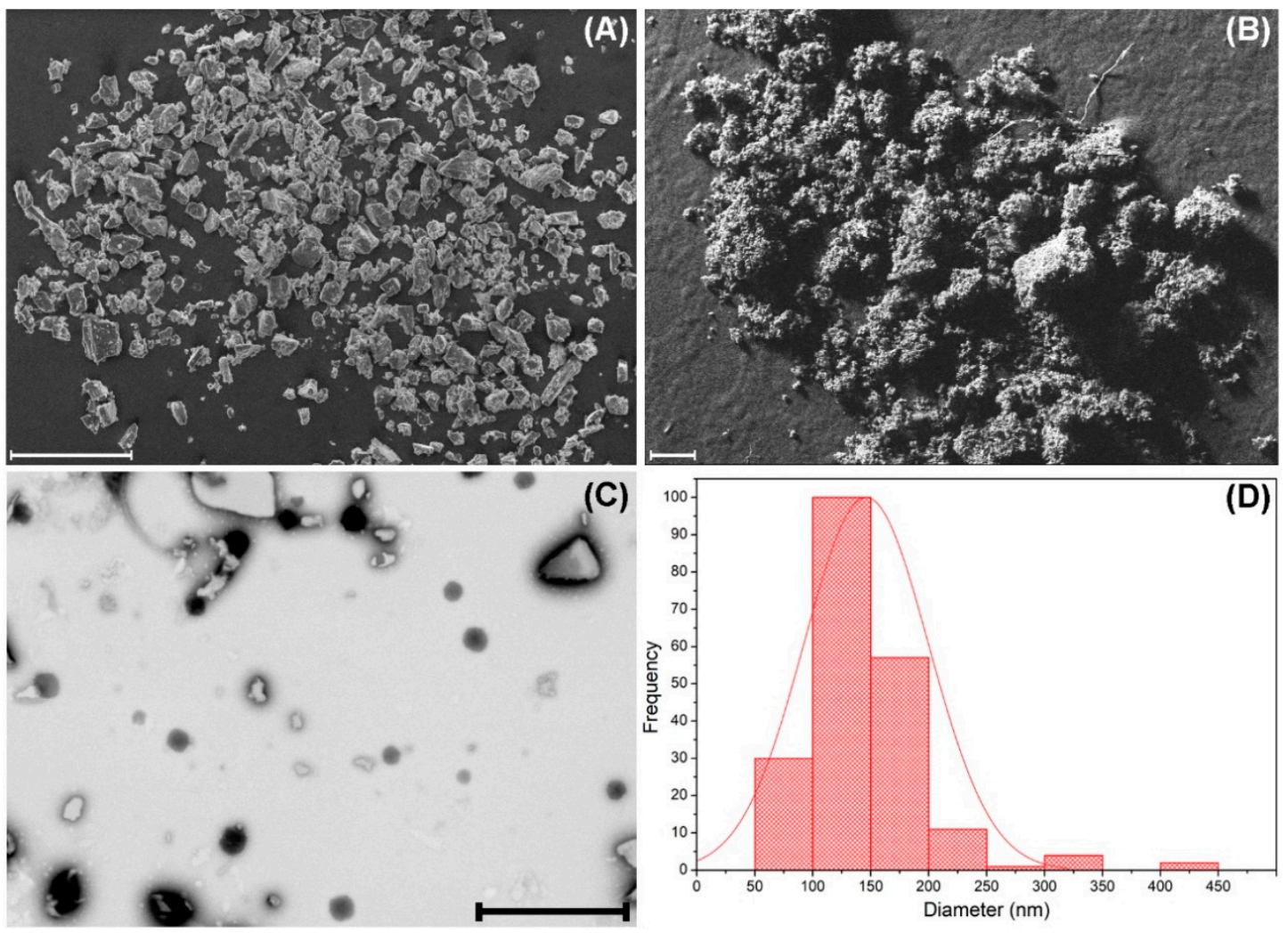

Figure 3. SEM micrographs of (A) $\beta C D$ and (B) $\beta C D N S$. (C) transmission electron microscopy (TEM) micrograph of $\beta C D N S$ and (D) the size distribution observed in TEM micrographs of $\beta C D N S$. Scale bar for figure (A) and (B) is $200 \mu \mathrm{m}$; scale bar for figure (C) is $1000 \mathrm{~nm}$.

\subsection{Loading of $\beta$-Cyclodextrin-Based Nanosponges with Drugs}

The $\beta C D N S$ obtained was loaded with two drugs separately, forming the $\beta C D N S-$ PhEA and $\beta C D N S-A T$ systems. Once each supramolecular complex was formed in the 
solubilized phase of the aqueous solution, the effective inclusion of the drugs and the stoichiometric relationship of both systems were analyzed using ${ }^{1} \mathrm{H}-\mathrm{NMR}$.

Figure 4 shows the spectra of $\beta C D N S-P h E A(A)$ and $\beta C D N S-A T$ (B) with their molecular structures and proton assignments for the respective drug. The loading of PhEA to form the $\beta C D N S-P h E A$ system (A) and the loading of AT to form the $\beta C D N S-A T$ system (B) were confirmed with the respective assignments of protons in the molecular structures of PhEA and AT (see full spectra, Figures A4 and A5, in Appendix B). Tables 2 and 3 show the chemical shifts and integrals recorded for the protons of $\beta C D N S$ and of the PhEA and AT drugs resulting from the inclusion process.

For the $\beta C D N S-P h E A$ system, Table 2, the largest chemical shifts for $\beta C D N S$ were observed for the internal protons $\mathrm{H} 3$ and $\mathrm{H} 5$ and the hydroxyl groups $\mathrm{OH} 2$ and $\mathrm{OH} 3$, probably due to preferential inclusion in the widest zone of the $\beta C D$ cavity. In addition, chemical shifts for all the $\beta C D N S$ protons were observed, mainly towards lower fields, which demonstrates the effective loading of PhEA within $\beta C D$ cavities and in the multiple interstitial spaces of the interstitial $\beta C D N S$ produced by crosslinking. Analyzing the chemical shifts of the PhEA protons, a change in the chemical environment due to inclusion was also evidenced, consistent with that reported in the literature $[25,71]$.

For the $\beta C D N S-A T$ system, Table 3 , chemical shifts were observed in all the $\beta C D N S$ protons oriented towards the interior and exterior of the cavity due to the change in the chemical environment of $\beta C D N S$ resulting from AT loading. This finding shows that the inclusion of the drug occurs in $\beta C D$ cavities and between the formed interstitial spaces. Chemical shifts towards higher fields were observed in the protons $\mathrm{NH}_{2} \mathrm{~b}, \mathrm{Hb}^{\prime} / \mathrm{f}^{\prime}$, and $\mathrm{Hc}^{\prime} / \mathrm{e}^{\prime}$ of $\mathrm{AT}$, which demonstrates the electronic shielding effect of the drug due to its inclusion in the nanosponges, in accordance with that reported in the literature [26].
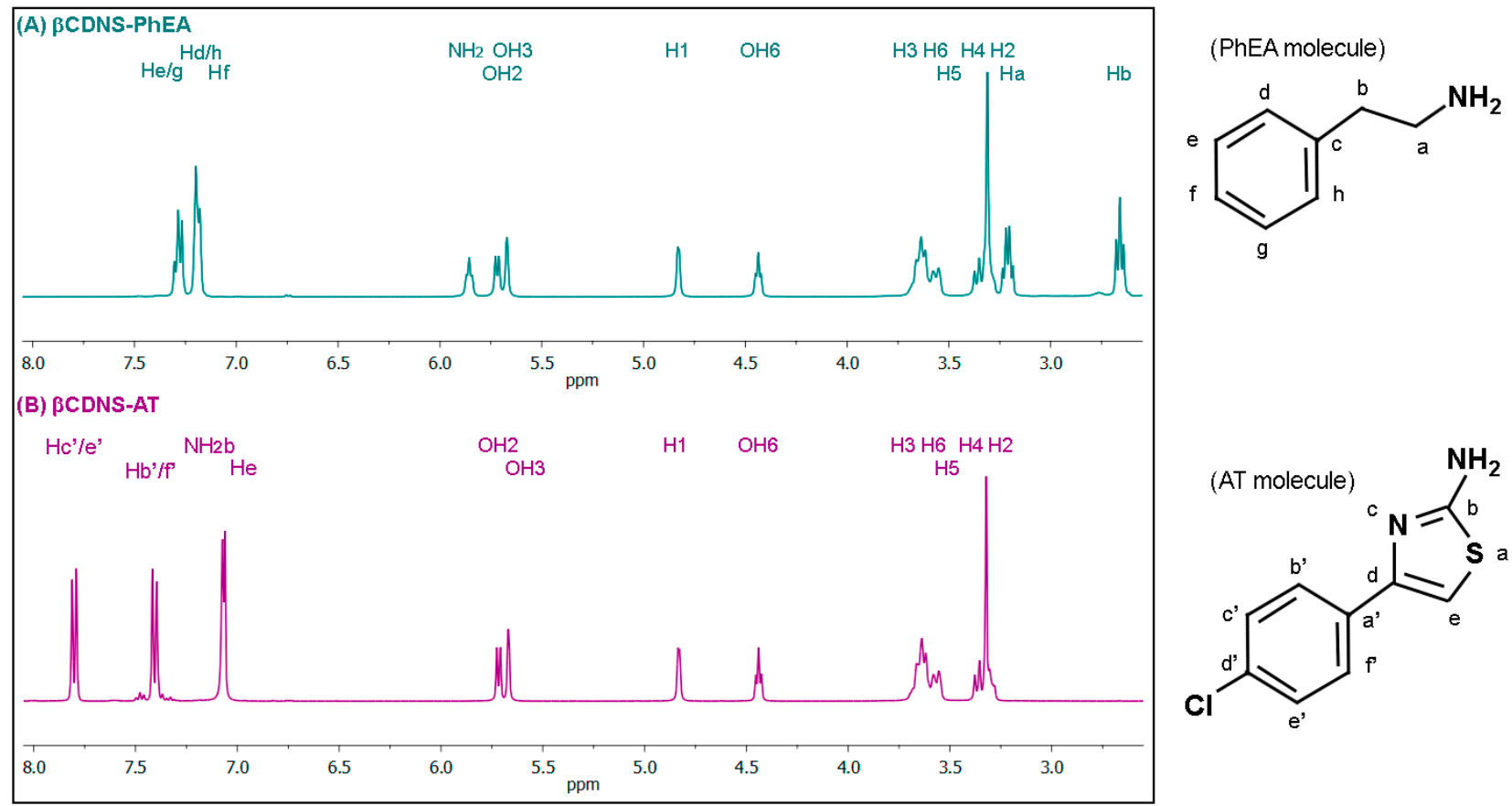

Figure 4. ${ }^{1} \mathrm{H}-\mathrm{NMR}$ spectra of (A) phenylethylamine (PhEA) loaded in $\beta C D N S$ ( $\left.\beta C D N S-P h E A\right)$ and (B) 2-amino-4-(4chlorophenyl)-thiazole (AT) loaded in $\beta$ CDNS ( $\beta C D N S-A T)$ (left) together with the molecular structures and the assigning protons with respect to PhEA and AT (right). 
Table 2. Proton assignments, ${ }^{1} \mathrm{H}-\mathrm{NMR}$ chemical shifts, and integrations of the $\beta C D N S$, phenylethylamine (PhEA), and PhEA loaded in $\beta C D N S$ ( $\beta C D N S-P h E A)$ signals.

\begin{tabular}{|c|c|c|c|c|c|}
\hline Proton & $\delta \beta C D N S(p p m)$ & $\begin{array}{c}\delta \beta C D N S-P h E A \\
\text { (ppm) }\end{array}$ & I $\Delta \delta \mid(p p m)$ & $\begin{array}{c}\beta C D N S \\
\text { Integration }\left(\int\right)\end{array}$ & $\begin{array}{c}\beta C D N S-P h E A \\
\text { Integration }\left(\int\right)\end{array}$ \\
\hline H1 & 4.827 & 4.829 & 0.002 & 7.00 & 7.00 \\
\hline $\mathrm{H} 2$ & 3.301 & - & - & 6.98 & - \\
\hline $\mathrm{H} 3$ & 3.655 & 3.660 & 0.005 & 6.98 & 6.96 \\
\hline $\mathrm{H} 4$ & 3.361 & 3.363 & 0.002 & 7.15 & 7.03 \\
\hline H5 & 3.562 & 3.565 & 0.003 & 7.04 & 7.05 \\
\hline H6 & 3.624 & 3.626 & 0.002 & 13.84 & 13.93 \\
\hline $\mathrm{OH} 2$ & 5.713 & 5.719 & 0.006 & 6.68 & 6.67 \\
\hline $\mathrm{OH} 3$ & 5.665 & 5.671 & 0.006 & 6.57 & 6.64 \\
\hline $\mathrm{OH} 6$ & 4.437 & 4.436 & 0.001 & 6.43 & 6.51 \\
\hline Proton & $\delta$ PhEA (ppm) & $\begin{array}{c}\delta \beta C D N S-P h E A \\
(\mathrm{ppm})\end{array}$ & I $\Delta \delta \mid(p p m)$ & $\begin{array}{c}\text { PhEAIntegration ( } \\
\left.\int\right)\end{array}$ & $\begin{array}{l}\beta C D N S-P h E A \\
\text { Integration }\left(\int\right)\end{array}$ \\
\hline $\mathrm{NH}_{2}$ & 1.385 & 5.856 & 4.471 & 2.05 & 7.07 \\
\hline $\mathrm{Ha}$ & 2.798 & 3.211 & 0.413 & 2.05 & 15.11 \\
\hline $\mathrm{Hb}$ & 2.658 & 2.660 & 0.002 & 2.07 & 16.05 \\
\hline $\mathrm{Hd} / \mathrm{h}$ & 7.205 & 7.198 & 0.007 & 1.97 & 16.00 \\
\hline $\mathrm{He} / \mathrm{g}$ & 7.285 & 7.284 & 0.001 & 2.00 & 16.02 \\
\hline $\mathrm{Hf}$ & 7.172 & 7.179 & 0.007 & 0.96 & 7.70 \\
\hline
\end{tabular}

Table 3. Proton assignments, ${ }^{1} \mathrm{H}$-NMR chemical shifts, and integrations of the $\beta$ CDNS, 2-amino-4-(4-chlorophenyl)-thiazole $(\mathrm{AT})$ and AT loaded in $\beta$ CDNS ( $\beta$ CDNS-AT) signals.

\begin{tabular}{|c|c|c|c|c|c|}
\hline Proton & $\delta \beta C D N S$ (ppm) & $\begin{array}{c}\delta \beta C D N S-A T \\
(\text { ppm) }\end{array}$ & | $\Delta \delta \mid(p p m)$ & $\begin{array}{c}\beta C D N S \\
\text { Integration }\left(\int\right)\end{array}$ & $\begin{array}{c}\beta C D N S-A T \\
\text { Integration }\left(\int\right)\end{array}$ \\
\hline H1 & 4.827 & 4.832 & 0.005 & 7.00 & 7.00 \\
\hline $\mathrm{H} 2$ & 3.301 & - & - & 6.98 & - \\
\hline H3 & 3.655 & 3.664 & 0.009 & 6.98 & 7.01 \\
\hline $\mathrm{H} 4$ & 3.361 & 3.367 & 0.006 & 7.15 & 7.09 \\
\hline H5 & 3.562 & 3.568 & 0.006 & 7.04 & 7.04 \\
\hline H6 & 3.624 & 3.629 & 0.005 & 13.84 & 13.86 \\
\hline $\mathrm{OH} 2$ & 5.713 & 5.717 & 0.004 & 6.68 & 6.70 \\
\hline $\mathrm{OH} 3$ & 5.665 & 5.669 & 0.004 & 6.57 & 6.53 \\
\hline OH6 & 4.437 & 4.440 & 0.003 & 6.43 & 6.53 \\
\hline Proton & $\delta \mathrm{AT}(\mathrm{ppm})$ & $\begin{array}{c}\delta \beta C D N S-A T \\
(p p m)\end{array}$ & | $\Delta \delta \mid(p p m)$ & AT Integration $\left(\int\right)$ & $\begin{array}{c}\beta C D N S-A T \\
\text { Integration }\left(\int\right)\end{array}$ \\
\hline $\mathrm{He}$ & 7.061 & 7.061 & 0.000 & 0.99 & 8.49 \\
\hline $\mathrm{NH} 2 \mathrm{~b}$ & 7.079 & 7.073 & 0.006 & 2.00 & 16.10 \\
\hline $\mathrm{Hb}^{\prime} / \mathrm{f}^{\prime}$ & 7.408 & 7.407 & 0.001 & 1.95 & 16.09 \\
\hline $\mathrm{Hc}^{\prime} / \mathrm{e}^{\prime}$ & 7.803 & 7.801 & 0.002 & 2.00 & 16.52 \\
\hline
\end{tabular}

Notably, the integration of the $\beta C D N S$ protons and the protons of each drug in their respective ${ }^{1} \mathrm{H}-\mathrm{NMR}$ spectra, Tables 2 and 3, showed a stoichiometric $\beta C D$ :drug ratio of 1:8 in both systems, which is an amount of drug eight times greater than those reported for $\beta C D-P h E A$ [25] and $\beta C D-A T$ [26], each of which exhibits a 1:1 stoichiometry. This amount is equivalent to $0.9 \mathrm{mg}$ of PhEA loading per $1 \mathrm{mg}$ of $\beta C D$ unit in $\beta C D N S$, and on the other hand, to $1.5 \mathrm{mg}$ of AT loading per $1 \mathrm{mg}$ of $\beta C D$ unit in $\beta C D N S$. Applying Equation (1) [58] (Section 2, Material and Methods), the loading capacity in $\beta C D N S$ is $90 \%$ for PhEA and $150 \%$ for AT, which is higher than the loading capacity of $11 \%$ for PhEA and $19 \%$ for AT in $\beta C D$ native, according to reported data $[25,26]$. These results show that the drug loading of the $\beta C D N S$ formed is higher than that of native $\beta C D$ and that $\beta C D N S$ could be used as a more efficient drug carrier than native $\beta C D$ (see the details in the Appendix $B$ ). 
The loading of drugs into $\beta$ CDNS was also analyzed by FT-IR spectroscopy by comparing peaks for vibrations before and after the inclusion process. Figure 5 shows the spectra of (A) PhEA, (B) $\beta C D N S-P h E A,(C)$ AT, and (D) $\beta C D N S-A T$.

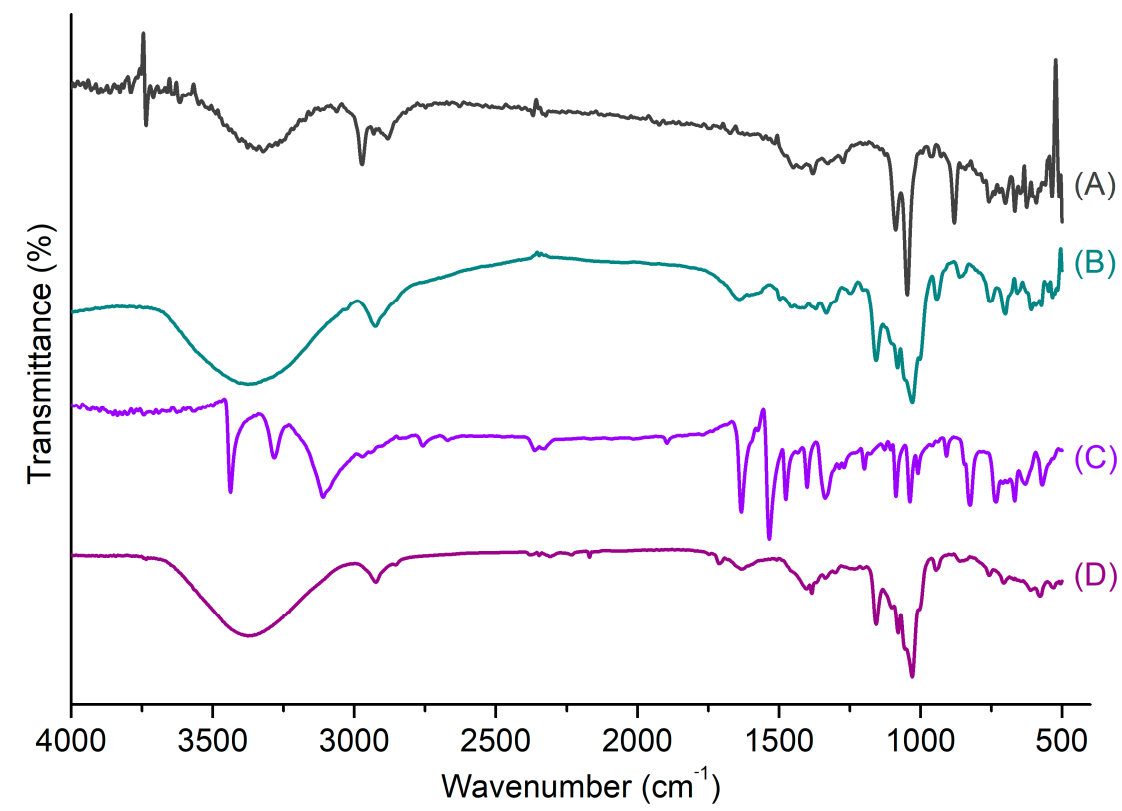

Figure 5. IR spectra of (A) phenylethylamine (PhEA), (B) PhEA loaded in $\beta C D N S$ ( $\beta C D N S-P h E A)$, (C) 2-amino-4-(4-chlorophenyl)-thiazole (AT), and (D) AT loaded in ßCDNS-AT.

In the vibrational analysis of the $\beta C D N S-P h E A$ system, the $\beta C D N S$ peaks at $3570 \mathrm{~cm}^{-1}$ and $3170 \mathrm{~cm}^{-1}$ corresponding to $\mathrm{O}-\mathrm{H}$ alcohol stretching and $\mathrm{N}-\mathrm{H}$ primary amine asymmetric and symmetric stretching, respectively, were identified. The peaks at $2926 \mathrm{~cm}^{-1}$ corresponding to $\mathrm{C}-\mathrm{H}$ stretching, at $1642 \mathrm{~cm}^{-1}$ corresponding to $\mathrm{C}=\mathrm{O}$ stretching, at $1333 \mathrm{~cm}^{-1}$ and $1157 \mathrm{~cm}^{-1}$ corresponding to $\mathrm{O}-\mathrm{H}$ bending, and at $1081 \mathrm{~cm}^{-1}$ and $1029 \mathrm{~cm}^{-1}$ corresponding to $\mathrm{C}-\mathrm{O}$ stretching were also identified. These vibrations remain unchanged in comparison to those of the $\beta C D N S$ spectrum without loaded drugs. The peak from PhEA found for the $\beta C D N S-P h E A$ system corresponding to $\mathrm{N}-\mathrm{H}$ symmetric stretching was observed at $2950 \mathrm{~cm}^{-1}$, while the peak at $745 \mathrm{~cm}^{-1}$ corresponding to C-H aromatics was masked due to the inclusion process.

In the case of the $\beta C D N S-A T$ system, decreases in the intensity of some peaks with respect to those of $\beta C D N S$ were observed. However, the characteristic peaks were located in the same regions of the spectra. O-H alcohol stretching, and N-H primary amine asymmetric and symmetric stretching vibrations were observed at $3170 \mathrm{~cm}^{-1}$ and $3570 \mathrm{~cm}^{-1}$, respectively. C-H stretching appeared at $2924 \mathrm{~cm}^{-1}, \mathrm{C}=\mathrm{O}$ stretching at $1637 \mathrm{~cm}^{-1}, \mathrm{O}-$ $\mathrm{H}$ group bending at $1384 \mathrm{~cm}^{-1}$ and $1157 \mathrm{~cm}^{-1}$, and finally, C-O stretching appeared at $1079 \mathrm{~cm}^{-1}$ and $1029 \mathrm{~cm}^{-1}$. The characteristic peaks of AT at $1476 \mathrm{~cm}^{-1}$, corresponding to $\mathrm{C}=\mathrm{C}$ aromatics, and at $3438 \mathrm{~cm}^{-1}$, corresponding to $\mathrm{N}-\mathrm{H}$ aromatic stretching, were masked in $\beta C D N S-A T$ due to the inclusion in $\beta C D N S$.

The changes in the intensity and definition of the $\beta C D N S$ peaks observed in the IR spectra suggested a change in their conformations due to drug loading, which was also corroborated by DLS and TEM. The hydrodynamic diameters of $\beta C D N S-P h E A$ and $\beta C D N S-A T$ were $270.5 \pm 48.0 \mathrm{~nm}$ and $335.5 \pm 150.5 \mathrm{~nm}$, respectively, observing an increase in the size of both systems with respect to $\beta C D N S$ (see more details in Appendix $C$ ). Figure 6 shows TEM images of $\beta C D N S$ loaded with PhEA (A-E) and AT (F-I). Changes in the shapes of the systems with respect to that of $\beta C D N S$ were also observed; in addition, the average diameter calculated using TEM images of these systems increased to $252 \pm 39 \mathrm{~nm}$ with respect to $\beta C D N S$. The loading of the drugs PhEA and AT could promote a process of 
association and intermolecular interactions between different $\beta C D N S$. This would explain the increase in size observed using TEM and DLS.
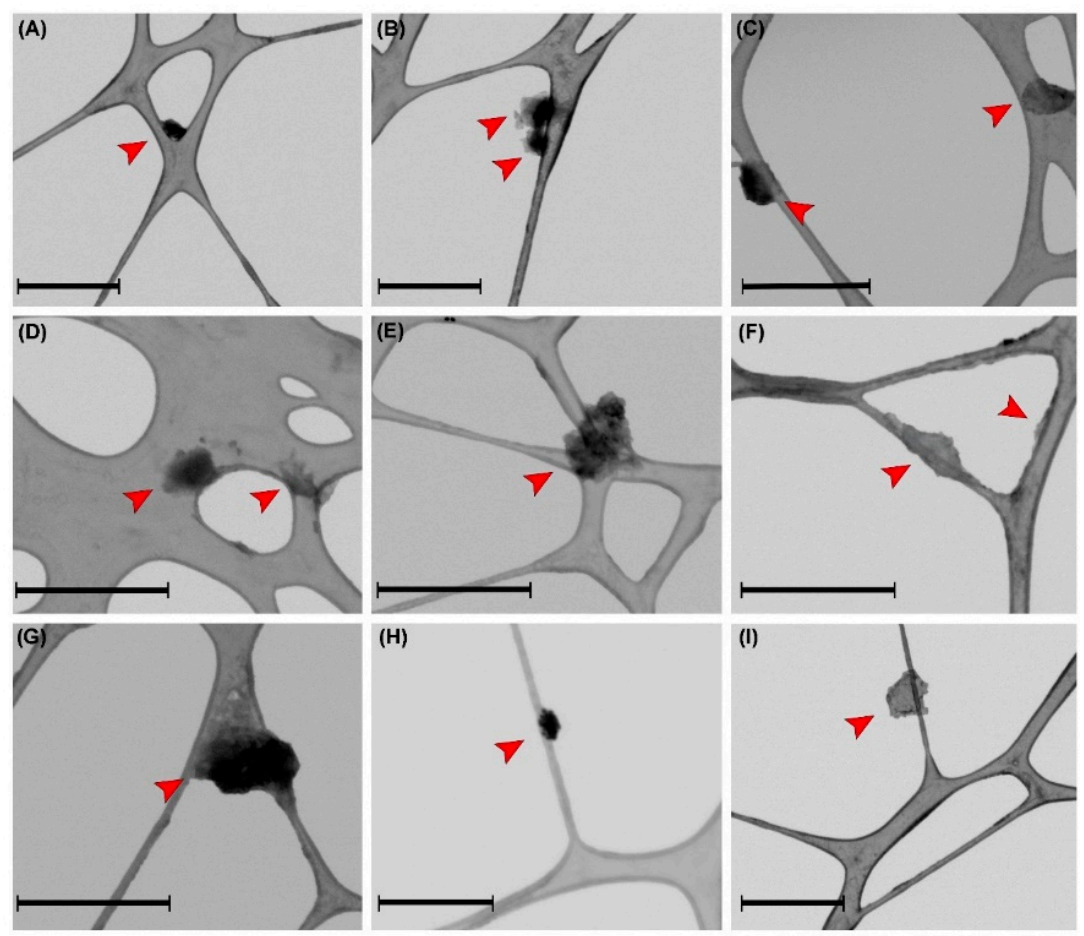

Figure 6. TEM micrographs of (A-E) $\beta C D N S-P h E A$ and (F-I) $\beta C D N S-A T$. Scale bar for all images is $1000 \mathrm{~nm}$ (Red arrows highlight the nanosystems in the micrographs).

The degree of solubilization indicates the tendency to increase the aqueous solubility of the drugs due to the action of $\beta C D N S$, while the complexation efficiency corresponds to the concentration of drug included versus the concentration of drug initially used in the process. This is directly related to the effectiveness of $\beta C D N S$ and intermolecular interactions to keep drugs entrapped in the complex. The degree of solubilization of the drugs, the $K_{a}$, and the complexation efficiency for the $\beta C D N S-P h E A$ and $\beta C D N S-A T$ systems were calculated using phase solubility studies (Equations (2) and (3), Section 2, Material and Methods) [59] and are shown in Table 4. Additionally, they were compared with the results obtained for the complexation of PhEA and AT using native $\beta C D[25,26]$.

An increase in the aqueous solubility of PhEA and AT using $\beta C D N S$ was observed, when they were compared to the solubility of free drugs (see Figures A7 and A8, Appendix B). Notably, the degree of solubilization achieved by the presence of $\beta C D N S$ was more than 1.3 times higher for PhEA and 5 times higher for AT than with native $\beta C D$. This is especially relevant in therapy since drugs to be pharmacologically active must be soluble in water. The $K_{a}$ values are $1318 \mathrm{M}^{-1}$ and $484 \mathrm{M}^{-1}$ for the $\beta C D N S-P h E A$ and $\beta C D N S-A T$ systems, respectively. These results indicate that the interactions that allow inclusion are strong, forming two highly stable systems over time due to the incorporation of $\beta C D N S$. The complexation efficiency values obtained for both systems show that the complexation using $\beta C D N S$ is optimal, being the same for PhEA in native $\beta C D$ and seven times greater for AT in native $\beta C D$. The above findings are in accordance with the previous discussion given by stoichiometry studies and loading capacity calculated using NMR (more details in the Appendix B). 
Table 4. Comparative data on the degree of solubilization, association constants, and complexation efficiency of the drugs PhEA and AT included in $\beta C D N S$ versus native $\beta C D$.

\begin{tabular}{cccc}
\hline System & $\begin{array}{c}\text { Degree of } \\
\text { Solubilization }\end{array}$ & $\mathbf{K}_{\mathbf{a}} \mathbf{( \mathbf { M } ^ { - \mathbf { 1 } } )}$ & $\begin{array}{c}\text { Complexation } \\
\text { Efficiency }\end{array}$ \\
\hline$\beta C D N S-P h E A$ & 0.035 & 1318 & 0.037 \\
$\beta C D N S-A T$ & 0.297 & 484 & 0.422 \\
$\beta C D-P h E A *$ & 0.028 & 760 & 0.038 \\
$\beta$ *D-AT * & 0.051 & 970 & 0.054 \\
\hline
\end{tabular}

* Reference values obtained from the literature $[25,26]$

In general, the $K_{a}$ values of the $\beta C D$ complexes vary between 50 and $2000 \mathrm{M}^{-1}$. Lower values at $50 \mathrm{M}^{-1}$ indicate a limitation in the pharmaceutical formulation since they have low stability and do not release the drug at its site of action [25,72-74]. On the other hand, $\mathrm{K}_{\mathrm{a}}$ values greater than $2000 \mathrm{M}^{-1}$ also present limitations, such as poor pharmacokinetics, since the drug release rates can be affected [72,73]. This is why the use of a strategy for the controlled release of the drugs included in $\beta C D N S$ becomes relevant. AuNPs can release absorbed energy in the form of heat and can release molecules near their surface as a result of the photothermal effect $[28,75,76]$. This was demonstrated for a drug in AuNPand $\beta C D$-based systems using laser irradiation $[25,47]$. In this sense, the incorporation of AuNPs into the two systems could, in addition to acting as a therapeutic agent, promote the controlled release of the drugs.

\subsection{Synthesis and Immobilization of Gold Nanoparticles on Drug-Loaded $\beta$-Cyclodextrin-Based Nanosponges}

Once the $\beta C D N S-$ drug systems were obtained, the interactions with colloidal AuNPs were studied to load another therapeutic agent and form the $\beta C D N S-P h E A-A u N P$ and $\beta C D N S-A T-A u N P$ systems. AuNPs were synthesized following the Turkevich method at $\mathrm{pH}$ 5.5. These AuNPs were then stabilized at $\mathrm{pH} 8.8$ to facilitate their immobilization on drug-loaded $\beta C D N S$. Figure 7A shows the absorbance spectra of AuNPs at $\mathrm{pH} 5.5$ and 8.8, and Figure 7B shows a representative TEM micrograph of spherical AuNPs with an average diameter of $18 \pm 4 \mathrm{~nm}$ (see histogram in Figure A9, Appendix C) AuNPs with diameters between 4 and $100 \mathrm{~nm}$ do not present cytotoxic effects [77], which would allow possible drug delivery applications.

Figure $7 \mathrm{C}, \mathrm{D}$ shows the UV-Vis spectra of the $\beta C D N S-P h E A-A u N P$ and $\beta C D-A T-$ AuNP systems, respectively, in addition to those of the initial AuNP solution and the supernatant resulting from the functionalization of each mixture. The recorded plasmon bands demonstrate a preferential interaction of AuNPs with $\beta C D N S-d r u g$, with an immobilization of $85 \%$, maintaining the main characteristics of the plasmon band and indicating that AuNPs remain stable in both systems.

Table 5 shows the intensities and the maximum wavelengths from the absorbance spectra. In addition, the hydrodynamic diameter and surface charge of $\beta C D N S-P h E A-$ AuNP and $\beta C D N S-A T-A u N P$ in aqueous solution are shown. These analyses represent the behavior of AuNPs in the different systems, because Au is highly efficient to absorb and scatter light, being superior to the organic material present.

A shift in the wavelength of the maximum absorbances with respect to those for the as-synthesized AuNPs occurred for both systems due to the interparticle coupling caused by the increased proximity between these nanostructures when immobilized; in turn, the permanence of the plasmon bands was evidence of the stability achieved and that the aggregation of AuNPs did not occur. In turn, increases in hydrodynamic diameters from $33.9 \pm 13.2 \mathrm{~nm}$ for AuNPs with citrate to $51.2 \pm 24.7 \mathrm{~nm}$ for AuNPs in the $\beta C D N S-$ PhEA-AuNP system and up to $114.0 \pm 42.2 \mathrm{~nm}$ for AuNPs in the $\beta C D N S-A T$ system were observed due to the proximity between the immobilized AuNPs and the presence of $\beta C D N S-$ drug complexes. Furthermore, this behavior was consistent with the increase in size of the $\beta C D N S$ when they were loaded with the drugs. The reported partial and dynamic inclusion of AT in $\beta C D$ could explain the greater hydrodynamic diameter of the 
AuNPs on $\beta C D N S-A T$ with respect to $\beta C D N S-P h E A$. The two functional groups, $\mathrm{NH}_{2}$ and $\mathrm{SH}$, of AT are exposed [26], facilitating its interaction with AuNPs, while PhEA only has one $\mathrm{NH}_{2}$ group that is completely included within $\beta C D[25,71]$.
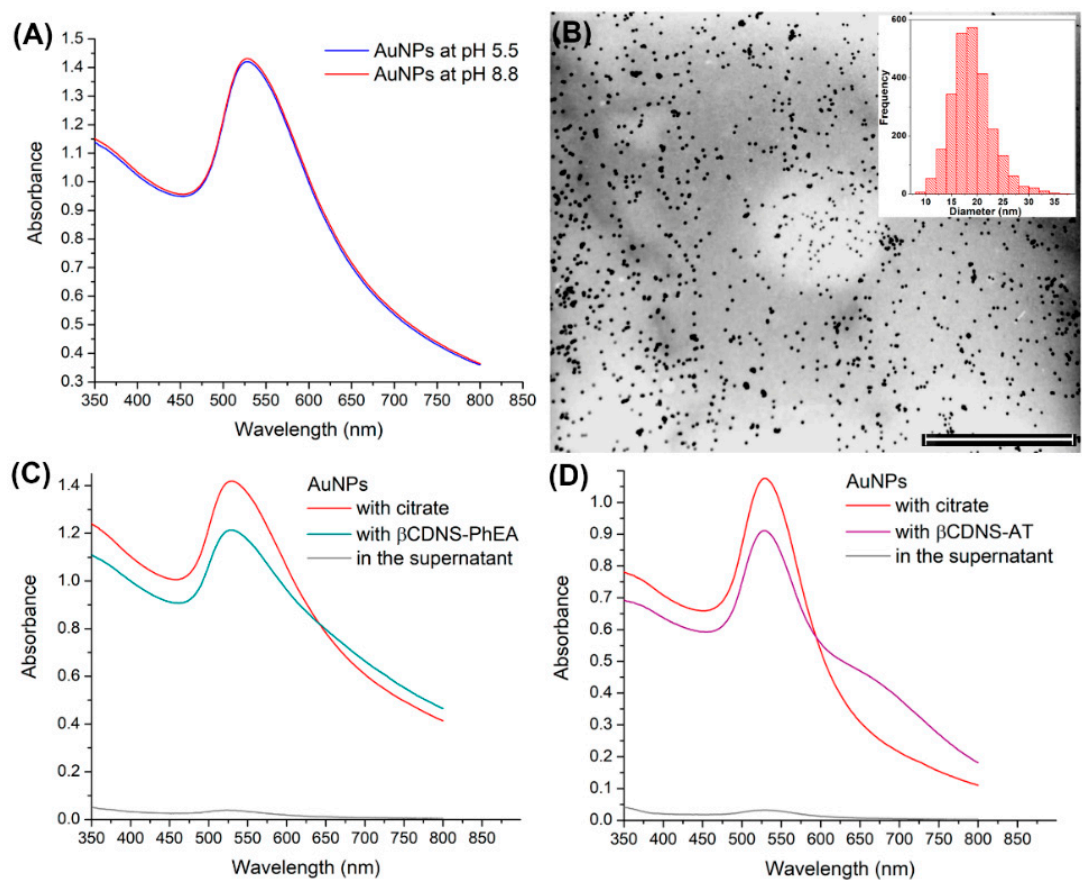

Figure 7. (A) UV-Vis spectra of AuNPs at pH 5.5 and pH 8.8; (B) TEM micrograph of AuNPs with their size histogram inserted (scale bar of $1000 \mathrm{~nm}$ ); (C) UV-Vis spectra of AuNPs with citrate and with $\beta C D N S-P h E A$, including supernatant of the functionalization; and (D) UV-Vis spectra of AuNPs with citrate and with $\beta C D N S-A T$, including supernatant of the functionalization.

The registered surface charge of the AuNPs was $-51.4 \pm 7.9 \mathrm{mV}$ due to the stabilizing citrate ions, which changed to $-33.0 \pm 5.3 \mathrm{mV}$ and $-38.4 \pm 6.9 \mathrm{mV}$ for AuNPs in the $\beta C D N S-P h E A-A u N P$ and in the $\beta C D N S-A T-A u N P$ systems, respectively, due to the replacement of a fraction of citrate molecules by neutral supramolecular complexes. As a control, a drug-free $\beta C D N S$ solution was subjected to the same mixing protocol with colloidal AuNPs, confirming through different characterization techniques that the interaction between $\beta C D N S$ and AuNPs does not occur (see the details in the Appendix C).

Table 5. Data obtained from the UV-VIS spectra, dynamic light scattering (DLS), and $\zeta$ potentials of the as-synthesized gold nanoparticles (AuNPs) and AuNPs immobilized on the $\beta C D N S-P h E A$ and $\beta C D N S-A T$ supramolecular systems.

\begin{tabular}{ccccccc}
\hline System & $\begin{array}{c}\text { Intensity (a.u.) } \\
\text { of } \mathbf{A}_{\text {max }}\end{array}$ & $\begin{array}{c}\text { Wavelength } \\
\text { (nm) of A } \mathbf{A}_{\text {max }}\end{array}$ & $\begin{array}{c}\text { Immobilized } \\
\text { AuNPs (\%) }\end{array}$ & $\begin{array}{c}\text { Hydrodynamic } \\
\text { Diameter (nm) }\end{array}$ & $\begin{array}{c}\text { PDI } \\
\text { Superficial } \\
\text { Charge (mV) }\end{array}$ \\
\hline AuNPs-citrate & 1.419 & 528 & 0 & $33.9 \pm 13.2$ & 0.537 & $-51.4 \pm 7.9$ \\
BCDNS-PhEA-AuNP & 1.214 & 529 & 85.5 & $51.2 \pm 24.7$ & 0.571 & $-33.0 \pm 5.3$ \\
BCDNS-AT-AuNP & 0.912 & 531 & 84.7 & $114.0 \pm 42.2$ & 0.663 & $-38.4 \pm 6.9$ \\
\hline
\end{tabular}

Figure $8 \mathrm{~A}, \mathrm{~B}$ shows SEM micrographs of the $\beta C D N S-P h E A-A u N P(A)$ and $\beta C D N S-$ AT-AuNP (B) systems, respectively. The images clearly show the AuNPs immobilized on the $\beta C D N S-$ drug supramolecular complexes. In addition, an irregular morphology was observed, probably due to the process of functionalization of $\beta C D N S$, as suggested by the TEM images (Figure 6).

Various characterization techniques and direct observation using electron microscopy confirmed the simultaneous loading of $\beta C D N S$ with two therapeutic agents, drugs and AuNPs, forming the $\beta C D N S-P h E A-A u N P$ and $\beta C D N S-A T-A u N P$ systems. If properly 
designed, that is, by establishing parameters for the colloidal stability, concentration, surface charge, and size, among others, $\beta C D N S$ and AuNPs could be considered nontoxic and used in therapy without generating adverse effects in the organism. In this sense, in the design and formation of these two new systems, the established parameters were realized.
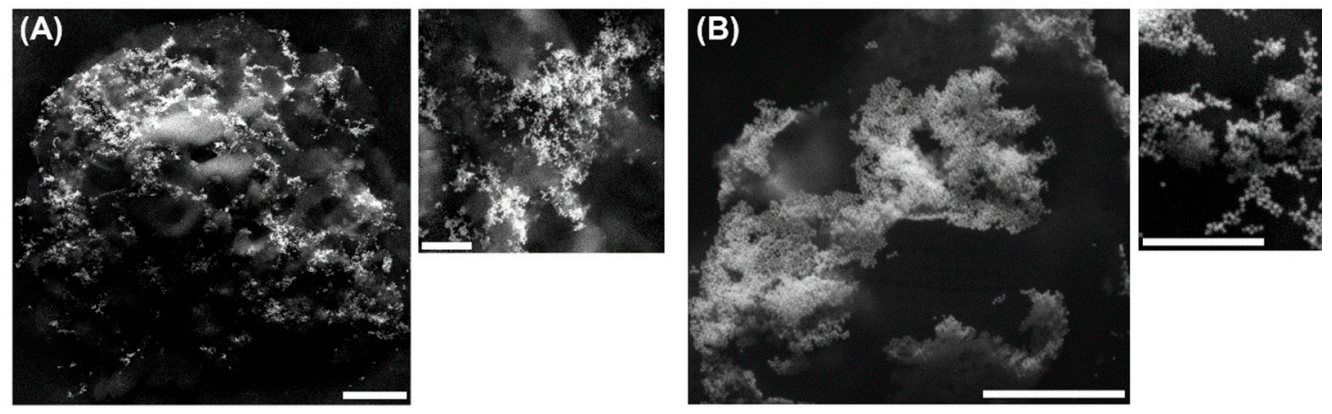

Figure 8. SEM micrographs of (A) $\beta C D N S-P h E A$ with gold nanoparticles (AuNPs) immobilized on the surface and a zoomed view, with bar scales of $2000 \mathrm{~nm}$ and $500 \mathrm{~nm}$; (B) $\beta C D N S-A T$ with AuNPs immobilized on its surface and a zoomed view, with bar scales of $1000 \mathrm{~nm}$ and $500 \mathrm{~nm}$.

\section{Conclusions}

The formation of $\beta C D N S$ was confirmed by different techniques that indicated its polymeric characteristics and nanometric dimensions. Therapeutic agents PhEA and AT were successfully included in the multiple cavities of the nanostructures, forming the $\beta C D N S-P h E A$ and $\beta C D N S-A T$ systems. The loading capacity of $\beta C D N S$ was $90 \%$ for PhEA and $150 \%$ for AT, being eight times higher than with native $\beta C D$. An increase in the aqueous solubility of PhEA and AT when complexed with $\beta C D N S$ was demonstrated. In addition, a higher degree of solubilization and complexation efficiency of both drugs was obtained with $\beta C D N S$ than with native $\beta C D$. The synthesized AuNPs were also loaded into each system, reaching an immobilization percentage of $85 \%$. The hydrodynamic diameter and surface charge of AuNPs were $51 \mathrm{~nm}$ and $-33 \mathrm{mV}$ in the $\beta C D N S-P h E A-A u N P$ system and $114 \mathrm{~nm}$ and $-38 \mathrm{mV}$ in the $\beta C D N S-A T-A u N P$ system, respectively, which are relevant parameters for biological studies. $\beta C D N S$ loaded with the two therapeutic agents (drug and AuNP) were observed directly by SEM images, showing the porous morphologies of the nanosponges and the nanoparticles immobilized on their surfaces due to the $\mathrm{SH}$ and $\mathrm{NH}_{2}$ functional groups of the drugs. We believe that these unique systems, based on $\beta C D N S$, drugs, and AuNPs, can be versatile materials with an efficient loading capacity for potential applications in the transport of therapeutic agents. Finally, to continue researching in the field of drug delivery, studies that demonstrate the controlled release of PhEA and AT from $\beta C D N S-$ drug-AuNP using laser irradiation are required and this, together with studies of cell permeability, toxicity, and pharmacological activity, has been considered in a future perspective.

Author Contributions: Conceptualization, I.A., N.Y. and R.S.; methodology, I.A., N.Y. and R.S.; validation, I.A. and R.S.; formal analysis, I.A., O.D.-G. and R.S.; investigation, I.A. and R.S.; resources, I.A., O.D.-G., N.Y. and R.S.; data curation, I.A. and R.S.; writing - original draft preparation, I.A., O.D.-G. and R.S.; writing-review and editing, I.A., O.D.-G., N.Y. and R.S.; visualization, I.A. and R.S.; supervision, I.A. and R.S.; project administration, I.A., N.Y. and R.S.; funding acquisition, I.A., O.D.-G., N.Y. and R.S. All authors have read and agreed to the published version of the manuscript.

Funding: Orlando Donoso-González gives thanks for financing of ANID doctoral scholarship No. 21180548. Rodrigo Sierpe gives thanks for financing to ANID-FONDECYT for postdoctoral research grant No. 3180706. Orlando Donoso and Rodrigo Sierpe acknowledge the financing of ANIDFONDAP No. 15130011.

Institutional Review Board Statement: Not applicable. 
Informed Consent Statement: Not applicable.

Data Availability Statement: Not applicable.

Conflicts of Interest: The authors declare no conflict of interest.

Appendix A

Appendix A.1. $\beta$-cyclodextrin Nanosponge Synthesis

The methods for the synthesis of $\beta C D N S$ were:

Appendix A.1.1. Method A. (Patel, 2014)

In a round-bottomed flask, $\beta C D$ was mixed with $\mathrm{DPC}$, and two different molar ratios were studied: $1: 4$ and 1:8. The flask was then placed in an ultrasonic bath at $90{ }^{\circ} \mathrm{C}$ for $5 \mathrm{~h}$. The solid product obtained was then repeatedly washed with distilled water and vacuum filtered for $2 \mathrm{~h}$ using a Kitasato flask with a Büchner funnel with filter paper. The product was washed for $24 \mathrm{~h}$ in a Soxhlet system, and two different solvents, ethanol and acetone, were studied for this process; the product was finally dried and stored in an amber flask with a Teflon seal.

\section{Appendix A.1.2. Method B. (Modified from Patel)}

In a round-bottomed flask, $\beta C D$ was mixed with $\mathrm{DPC}$, and two different molar ratios were studied: 1:4 and 1:8. The flask was heated in an oil bath on a heating plate with constant agitation for $5 \mathrm{~h}$ at $100{ }^{\circ} \mathrm{C}$. The mouth of the flask was covered with a septum, and a syringe was introduced into it to let the phenol gas released from the reaction pass through. The solid mixture obtained was extracted from the flask, a small amount of water was added and an ultrasonic bath was used to release residues from the walls. Once all the solid was extracted, it was ground in a mortar, washed with distilled water, and then vacuum filtered for $2 \mathrm{~h}$. The product was washed for $24 \mathrm{~h}$, and two different solvents, ethanol and acetone, were studied for this process: ethanol and acetone. Finally, the product was dried for between 48 and $72 \mathrm{~h}$ at $65^{\circ} \mathrm{C}$ and stored.

Figure A1 shows a bar graph with the mass yields of different types of $\beta C D N S$ syntheses with changes in the heating method, the solvents used in the washing steps and the $\beta C D: D P C$ molar ratio.

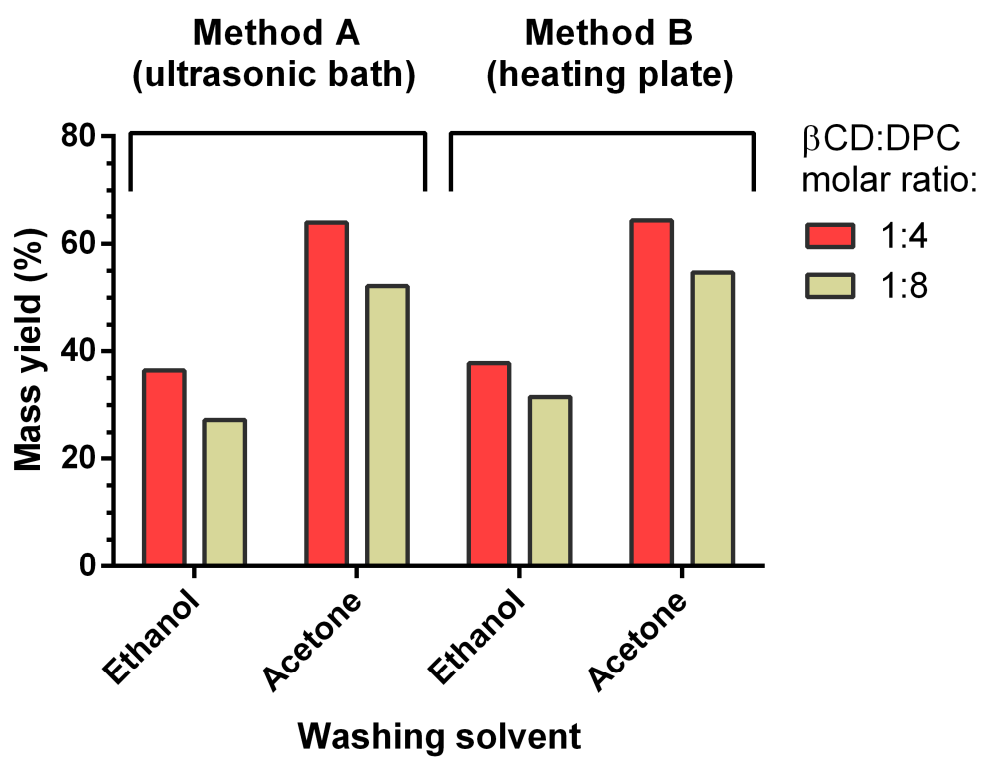

Figure A1. Mass yield (in percentage) of $\beta C D N S$ versus the washing solvent, heating method and $\beta C D: D P C$ molar ratio. 
Appendix A.2. Derivative Curves from TGA Characterization of $\beta$-Cyclodextrin Nanosponge

Figure A2 shows the derivative curves from TGA (Figure 2B), analysing the differences in the peaks of the thermogravimetric decomposition curves.

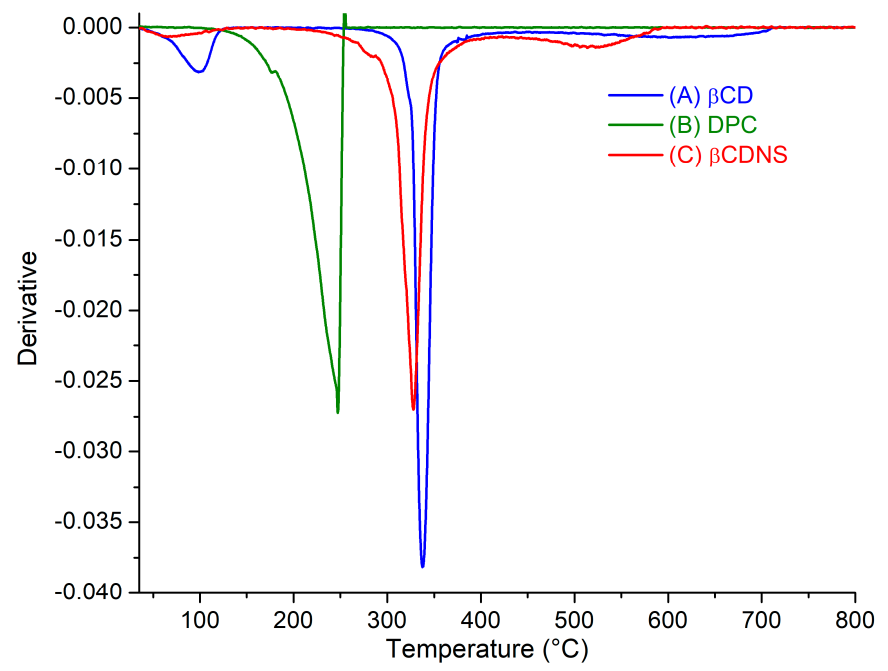

Figure A2. TGA derivative curves of (A) $\beta C D$, (B) DPC and (C) $\beta C D$.

Appendix A.3. TEM Characterization of Native $\beta$-Cyclodextrin

Figure $\mathrm{A} 3$ shows a TEM image of Figure A3A-C $\beta C D N S$ to obtain its mean size; and Figure $\mathrm{A} 3 \mathrm{D}$ native $\beta C D$ with the same dispersion and staining protocol described for $\beta C D N S$.

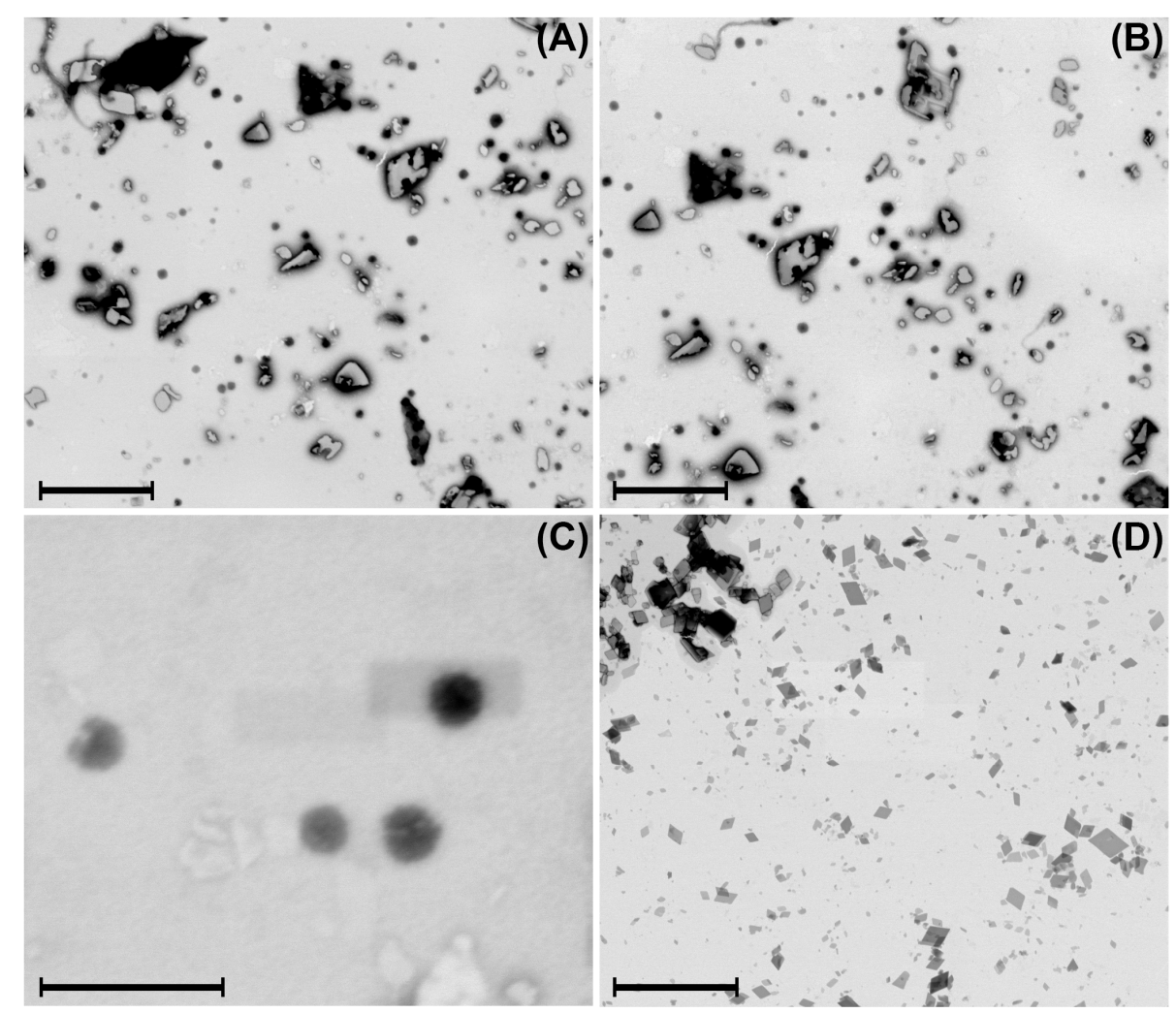

Figure A3. TEM micrographs of: (A,B) $\beta C D N S$ with bar scales of $2000 \mathrm{~nm}$; (C) $\beta C D N S$ with bar scale of $400 \mathrm{~nm}$; and (D) native $\beta C D$ with bar scale of $4000 \mathrm{~nm}$. Acceleration voltage used: $10.0 \mathrm{kV}$. 


\section{Appendix B}

Appendix B.1. ${ }^{1}$ H-NMR Full Spectra of Loading Drugs Process

Figures A4 and A5 show the full ${ }^{1} \mathrm{H}-\mathrm{NMR}$ spectra of $\beta C D N S$, PhEA, AT, $\beta C D N S-P h E A$ and $\beta C D N S-A T$, summarized in Figure 4.

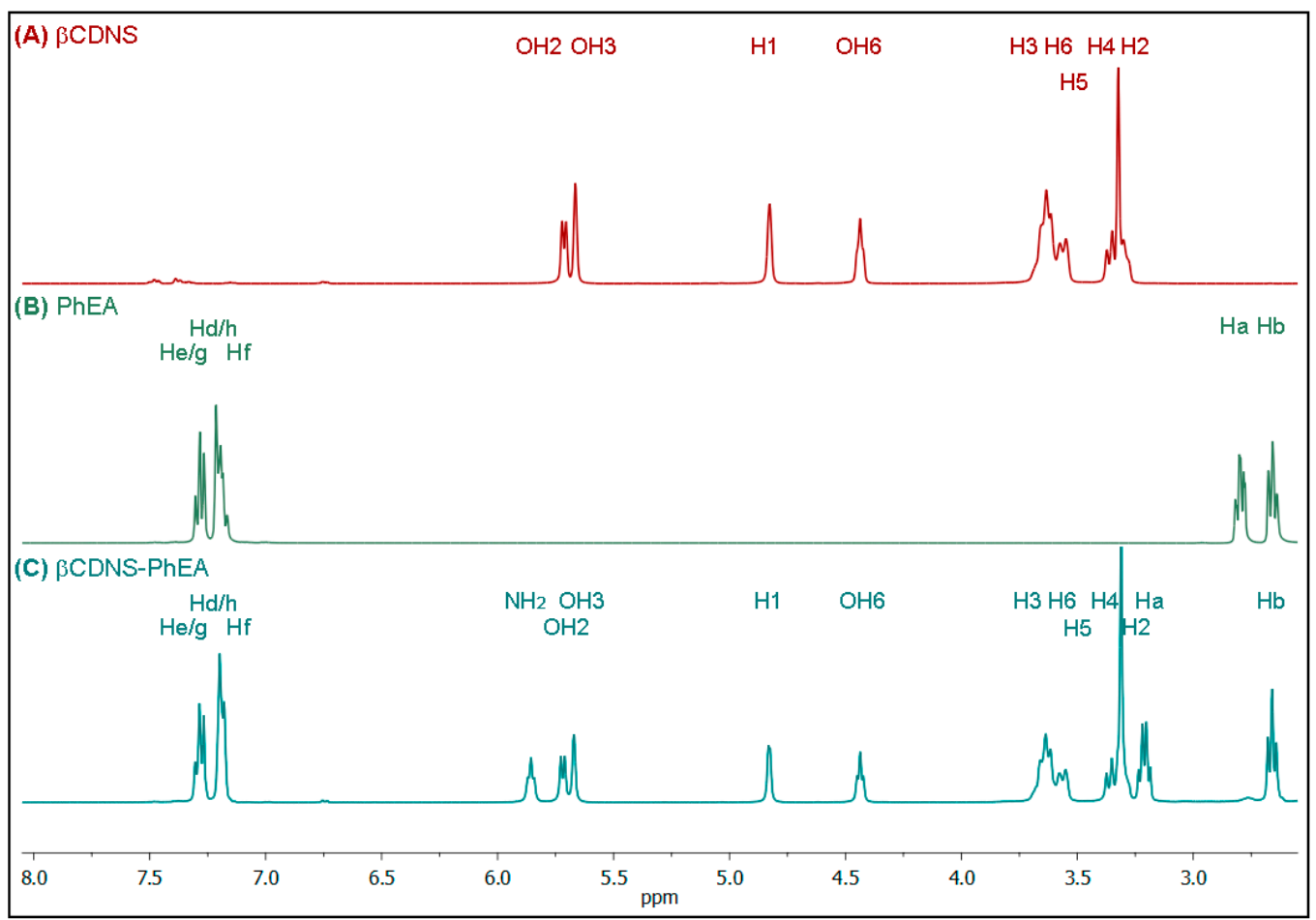

Figure A4. ${ }^{1} \mathrm{H}-\mathrm{NMR}$ spectra of (A) $\beta C D N S,(B)$ PhEA and (C) $\beta C D N S-P h E A$.

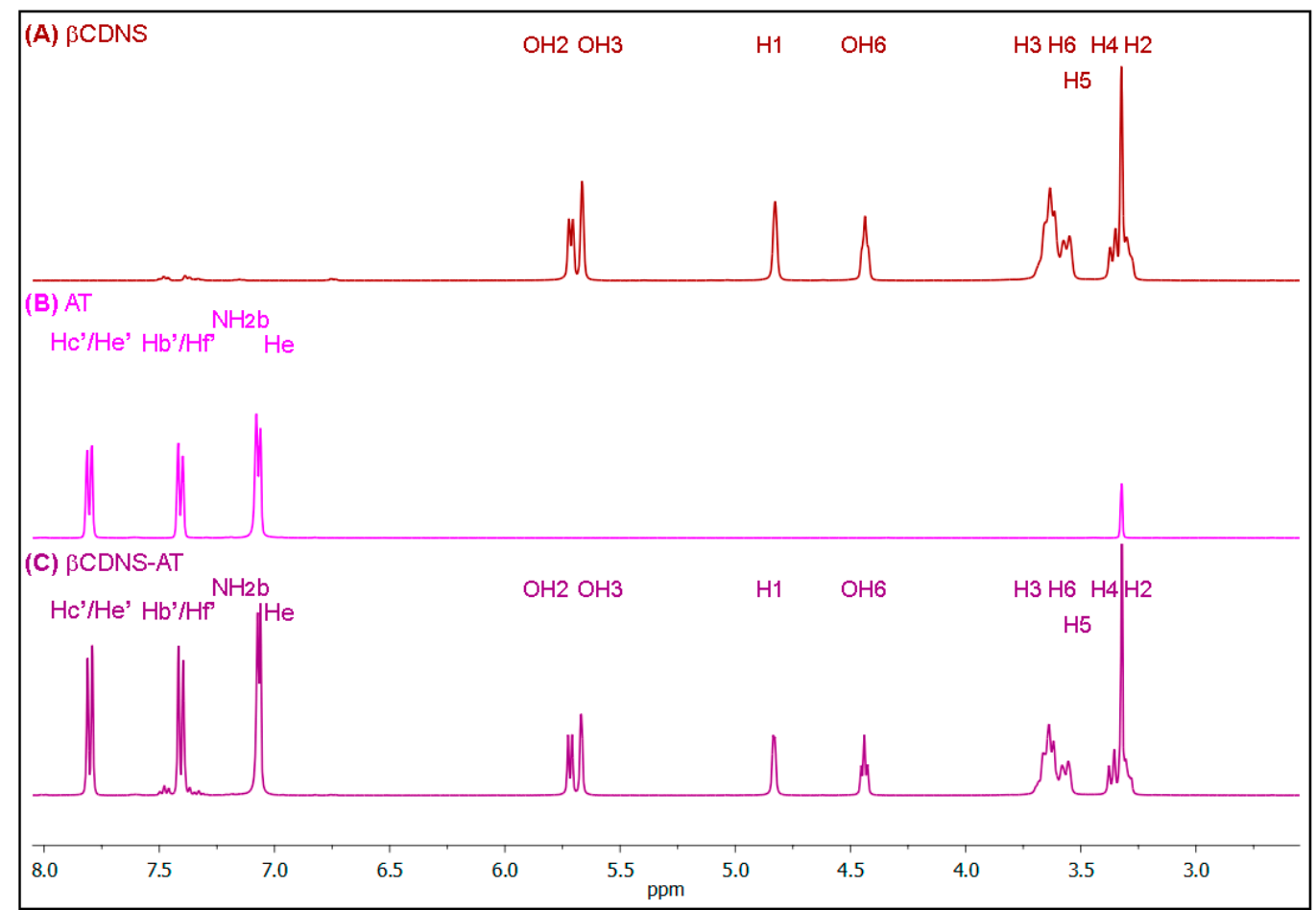

Figure A5. ${ }^{1} \mathrm{H}-\mathrm{NMR}$ spectra of (A) $\beta \mathrm{CDNS}$ (B) AT and (C) $\beta \mathrm{CDNS}-\mathrm{AT}$. 


\section{Appendix B.2. Calculation of the Stoichiometric Ratio of the Drug Loading Process}

The stoichiometric ratios were calculated in the ${ }^{1} \mathrm{H}-\mathrm{NMR}$ spectra by comparing the integrals of the PhEA and AT protons with the integrals of the $\beta C D N S$ protons from the $\beta C D N S-P h E A$ and $\beta C D N S-A T$ systems. First, the integrals of the PhEA signals (protons $\mathrm{He} / \mathrm{g}, \mathrm{Hd} / \mathrm{h}$, and $\mathrm{Hf}$ ) were analysed using the $\mathrm{H} 1$ signal of $\beta C D N S$ as reference, which integrated 7. In turn, the integrals of the AT signals $\left(\mathrm{He}, \mathrm{Hb}^{\prime} / \mathrm{f}^{\prime}, \mathrm{Hc}^{\prime} / \mathrm{e}^{\prime}\right.$ and $\left.\mathrm{NH}_{2} \mathrm{~b}\right)$ were analysed using the $\mathrm{H} 1$ signal of $\beta C D N S$ as reference, which integrated 7 (see the data in Tables A1 and A2). Finally, the stoichiometric ratios calculated are summarized in Table A3.

Table A1. Values of the integrated PhEA and $\beta C D$ proton signals in the ${ }^{1} \mathrm{H}-\mathrm{NMR}$ spectra of the $\beta C D N S-P h E A$ system, with the integrated $\mathrm{H} 1$ proton signals of $\beta C D N S$ as a reference.

\begin{tabular}{ccccc}
\hline Proton Signal & Reference & Integral & Counts & Ratios \\
\hline $\mathrm{H} 1$ & 7 & 7.0 & 1 & 1 \\
$\mathrm{He} / \mathrm{g}$ & 2 & 16.0 & 8.0 & 8 \\
$\mathrm{Hd} / \mathrm{h}$ & 2 & 16.0 & 8.0 & 8 \\
$\mathrm{Hf}$ & 1 & 7.7 & 7.7 & 8 \\
\hline
\end{tabular}

Table A2. Values of the integrated AT and $\beta C D$ proton signals in the ${ }^{1} \mathrm{H}-\mathrm{NMR}$ spectra of the $\beta C D N S-A T$ system, with the integrated $\mathrm{H} 1$ proton signals of $\beta C D N S$ as a reference.

\begin{tabular}{ccccc}
\hline Proton Signal & Reference & Integral & Counts & Ratios \\
\hline $\mathrm{H} 1$ & 7 & 7 & 1 & 1 \\
$\mathrm{He}$ & 1 & 8.5 & 8.5 & 8 \\
$\mathrm{Hb}^{\prime} / \mathrm{f}^{\prime}$ & 2 & 16.1 & 8.1 & 8 \\
$\mathrm{Hc}^{\prime} / \mathrm{e}^{\prime}$ & 2 & 16.1 & 8.1 & 8 \\
$\mathrm{NH}_{2} \mathrm{~b}$ & 2 & 16.5 & 8.3 & 8 \\
\hline
\end{tabular}

Table A3. Summary of the molar ratios of the drugs in the $\beta C D N S$ for $\beta C D N S-d r u g$ systems calculated from Tables A1 and A2.

\begin{tabular}{ccc}
\hline & Molar Ratios & \\
\hline System & $\beta$ CDNS & Drug \\
\hline$\beta$ CDNS-PhEA & 1 & $8( \pm 0.3)$ \\
$\beta$ CDNS-AT & 1 & $8( \pm 0.4)$ \\
\hline
\end{tabular}

\section{Appendix B.3. Extinction Coefficient Determination of Drugs}

For each drug, a calibration curve was made with stocks of aqueous solutions of known concentrations to obtain the value of $\varepsilon$. Table A4 presents the data used for this determination for PhEA and AT.

Table A4. Data on the concentrations of the drugs, PhEA and AT, and their absorbance maxima at 310 and $290 \mathrm{~nm}$, respectively.

\begin{tabular}{cccc}
\hline [PhEA] $(\mathbf{m M})$ & Absorbance & [AT] $(\mathbf{m M})$ & Absorbance \\
\hline 0.0441 & 0.2441 & 0.095 & 0.078 \\
0.0882 & 0.3648 & 0.190 & 0.172 \\
0.1323 & 0.5642 & 0.285 & 0.305 \\
0.1764 & 0.7851 & 0.380 & 0.370 \\
0.2205 & 1.0267 & 0.569 & 0.518 \\
0.2646 & 1.3023 & 0.759 & 0.609 \\
0.3087 & 1.4199 & - & - \\
\hline
\end{tabular}

By plotting the PhEA concentration versus the maximum absorbance at $310 \mathrm{~nm}$, the line shown in Figure A6A was obtained, and the value of $\varepsilon$ was $4.7497 \pm 0.2110 \mathrm{mM}^{-1} \mathrm{~cm}^{-1}$. 
By plotting the AT concentration versus the maximum absorbance at $290 \mathrm{~nm}$, the line presented in Figure $\mathrm{A} 6 \mathrm{~B}$ was obtained; the slope corresponds to the value of $\varepsilon$, which was $0.8031 \pm 0.0692 \mathrm{mM}^{-1} \mathrm{~cm}^{-1}$.

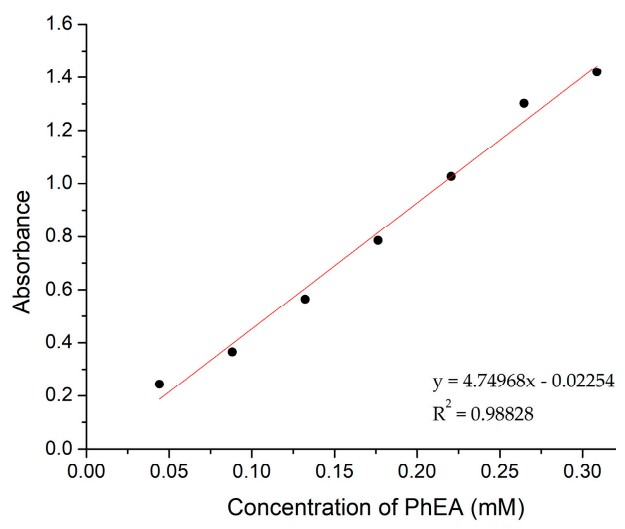

(A)

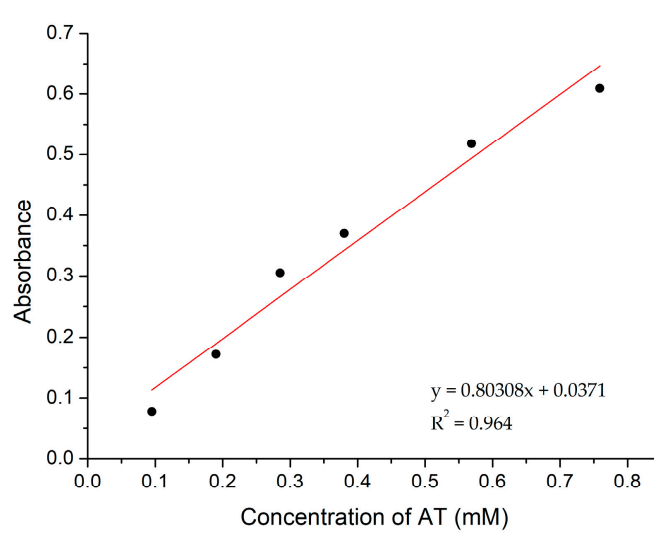

(B)

Figure A6. Linear plots of the (A) PhEA and (B) AT absorbance maxima at 310 and $290 \mathrm{~nm}$, respectively, vs. concentrations.

\section{Appendix B.4. Determinations of Association Constants of Drug Loading Systems}

For the determination of $K_{a}$, a stock solution was prepared with $200 \mathrm{mg}$ of $\beta C D N S$ and water in a $25 \mathrm{~mL}$ measuring flask. Volumes of 0 to $2 \mathrm{~mL}$ of the stock were taken and diluted with water to produce a total volume of $2 \mathrm{~mL}$ with a fixed amount of each drug, $0.5 \mathrm{~mL}$ for PhEA and $5.0 \mathrm{mg}$ for AT, added. All the data obtained are presented in Table A5 for PhEA and Table A6 for AT. By applying the extinction coefficient value $\varepsilon$ to the Lambert-Beer equation, it was possible to determine the PhEA and AT concentrations in the different assays using the Higuchi-Connors method.

Table A5. Values of the different tests carried out to calculate the $K_{a}$ and complexation efficiency of the $\beta C D N S-P h E A$ system in water.

\begin{tabular}{ccc}
\hline $\begin{array}{c}{[\beta \mathrm{CDNS}]} \\
(\mathbf{m M})\end{array}$ & Absorbance & $\begin{array}{c}{[\text { PhEA] }} \\
(\mathbf{m M})\end{array}$ \\
\hline 5.920 & 1.126 & 0.237 \\
5.328 & 1.006 & 0.212 \\
4.736 & 0.896 & 0.189 \\
4.144 & 0.775 & 0.163 \\
3.552 & 0.654 & 0.138 \\
2.960 & 0.564 & 0.119 \\
2.368 & 0.478 & 0.101 \\
1.776 & 0.404 & 0.085 \\
0 & 0.132 & 0.028 \\
\hline
\end{tabular}

Table A6. Values of the different tests carried out to calculate the $K_{a}$ and complexation efficiency of the $\beta C D N S-A T$ system in water.

\begin{tabular}{ccc}
\hline [ $\beta$ CDNS] $(\mathbf{m M})$ & Absorbance & [AT] $(\mathbf{m M})$ \\
\hline 4.736 & 1.833 & 2.282 \\
3.552 & 1.566 & 1.950 \\
2.960 & 1.343 & 1.672 \\
2.368 & 1.178 & 1.467 \\
1.776 & 1.19 & 1.482 \\
1.184 & 1.088 & 1.355 \\
0.592 & 0.739 & 0.920 \\
0 & 0.7 & 0.872 \\
\hline
\end{tabular}


The linear relationship obtained from a plot of the solubilized PhEA concentration versus the added $\beta C D N S$ concentration is shown in Figure A7. The value of the slope was $0.03534( \pm 0.00115)$. Using Equation (1), the association constant $\mathrm{K}_{\mathrm{a}}$ was calculated, resulting in a value of $1318 \mathrm{M}^{-1}$. Finally, using Equation (2), the value of complexation efficiency was calculated, resulting in a value of 0.03663 for the $\beta C D N S-P h E A$ system.

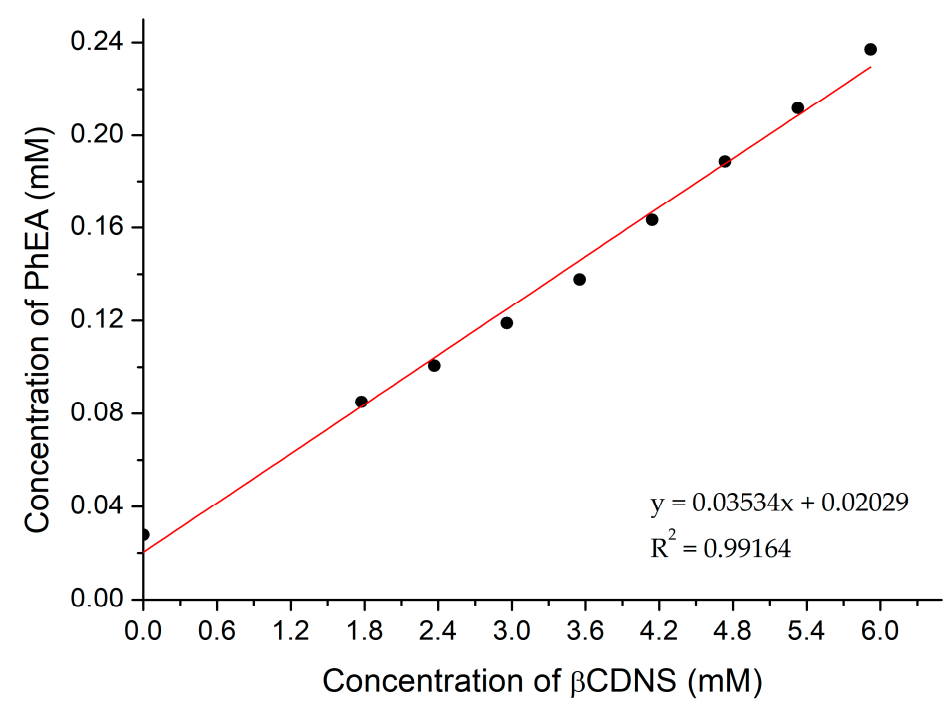

Figure A7. Graph of the concentration of solubilized PhEA versus the concentration of added $\beta C D N S$ and the linear fit.

Figure A8 shows the linear relationship obtained from a plot of the solubilized AT concentrations versus the added $\beta C D N S$ concentration. The value of the slope was 0.297 $( \pm 0.024)$. The $\mathrm{K}_{\mathrm{a}}$ for the $\beta C D N S-A T$ system was $484 \mathrm{M}^{-1}$ and the complexation efficiency value was 0.422 .

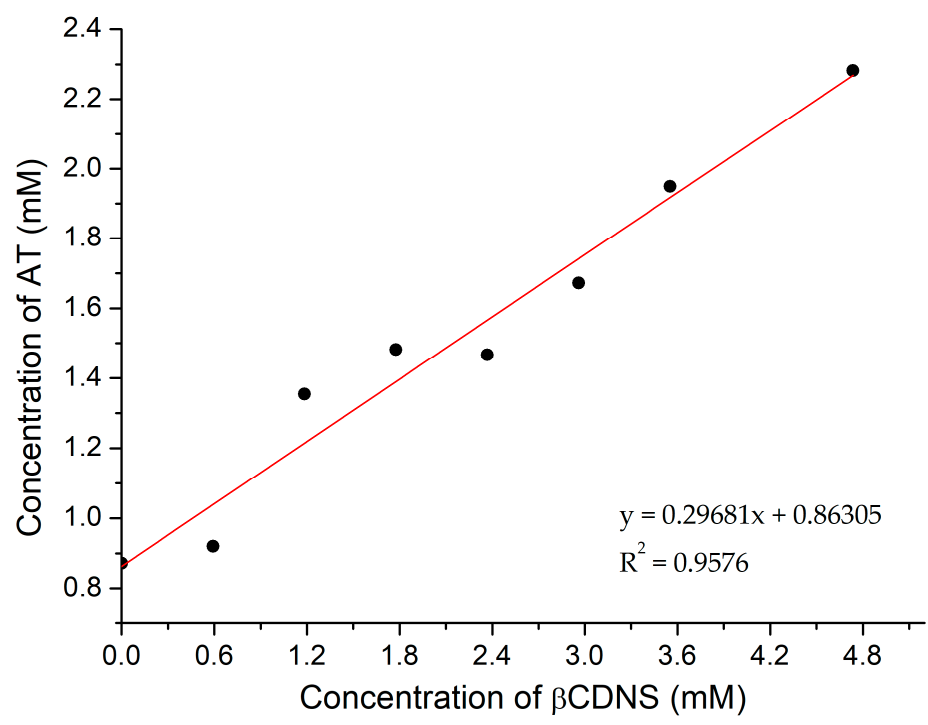

Figure A8. Graph of the concentration of solubilized AT versus the concentration of added $\beta C D N S$ and the linear fit.

\section{Appendix C}

Appendix C.1. Size Histogram of Gold Nanoparticles

Figure A9 shows the size distribution histogram for synthesised AuNPs from representative TEM images. The observed diameter was $18( \pm 4) \mathrm{nm}$. 


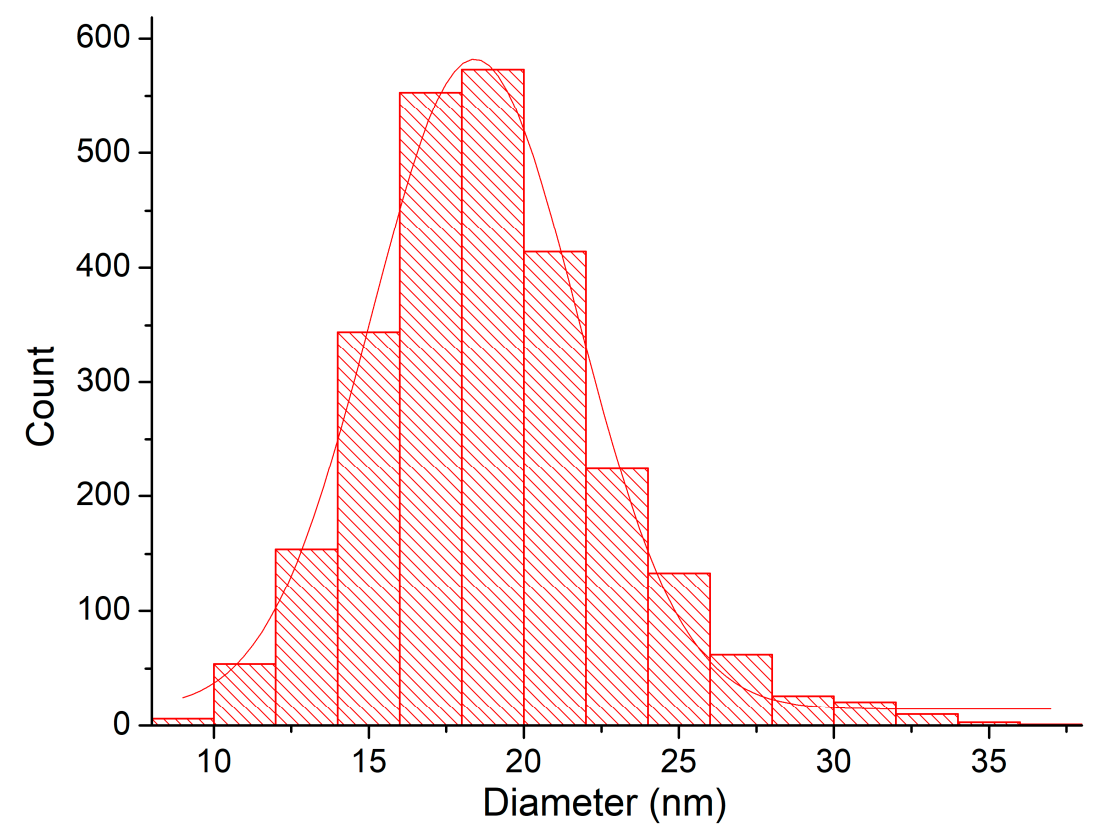

Figure A9. Histogram of size distribution of synthesised AuNPs.

Appendix C.2. Dynamic Light Scattering and $\zeta$ Potential Studies of Loading Systems and Gold Nanoparticles Interacting with Supramolecular Systems

The studies using DLS and the $\zeta$ potential are summarized in Table A7. $\beta C D N S$ was dispersed in water ( $\mathrm{pH} 8.8$ ) and measured, while $\beta C D N S-d r u g$ systems were sonicated and measured. AuNPs stabilized with citrate were filtered and then characterized. AuNPs with $\beta C D N S$ and drugs were centrifuged and resuspended in water $(\mathrm{pH} 8.8$ ) prior to characterization.

Table A7. Data obtained using dynamic light scattering (DLS) and the $\zeta$ potential of $\beta C D N S$ and $\beta C D N S-d r u g s$, and AuNPs with citrate, $\beta C D N S, \beta C D N S-P h E A$ and $\beta C D N S-A T$.

\begin{tabular}{ccccc}
\hline System & Hydrodynamic Diameter $(\mathbf{n m})$ & Intensity Peak Area $(\mathbf{\%})$ & PDI & Surface Charge $(\mathbf{m V})$ \\
\hline$\beta C D N S$ & $133.9 \pm 66.9$ & 100.0 & 0.197 & \\
$\beta C D N S-P h E A$ & $270.5 \pm 48.0$ & 87.0 & 0.398 & \\
$\beta$ CDNS-AT & $335.5 \pm 150.5$ & 89.0 & 0.355 & \\
AuNPs-citrate & $33.9 \pm 13.2$ & 69.7 & 0.537 & $-51.40 \pm 7.86$ \\
AuNPs- $\beta$ CDNS & $34.6 \pm 12.9$ & 70.0 & 0.542 & $-58.03 \pm 7.01$ \\
$\beta$ CDNS-PhEA-AuNP & $51.2 \pm 24.7$ & 85.8 & 0.571 & $-33.03 \pm 5.26$ \\
$\beta$ CDNS-AT-AuNP & $114.0 \pm 42.2$ & 86.3 & 0.663 & $-38.37 \pm 6.90$ \\
\hline
\end{tabular}

\section{References}

1. Kurkov, S.V.; Loftsson, T. Cyclodextrins. Int. J. Pharm. 2013, 453, 167-180. [CrossRef] [PubMed]

2. Hartlieb, K.J.; Holcroft, J.M.; Moghadam, P.Z.; Vermeulen, N.A.; Algaradah, M.M.; Nassar, M.S.; Botros, Y.Y.; Snurr, R.Q.; Stoddart, J.F. CD-MOF: A versatile separation medium. J. Am. Chem. Soc. 2016, 138, 2292-2301. [CrossRef]

3. Ma, X.; Zhao, Y. Biomedical applications of supramolecular systems based on host-guest interactions. Chem. Rev. 2015, 115, 7794-7839. [CrossRef]

4. Mejia-Ariza, R.; Graña-Suárez, L.; Verboom, W.; Huskens, J. Cyclodextrin-based supramolecular nanoparticles for biomedical applications. J. Mater. Chem. B 2017, 5, 36-52. [CrossRef] [PubMed]

5. Wang, Y.; Liu, Y.; Liang, J.; Zou, M. A cyclodextrin-core star copolymer with Y-shaped ABC miktoarms and its unimolecular micelles. RSC Adv. 2017, 7, 11691-11700. [CrossRef]

6. Zhang, J.; Ma, P.X. Cyclodextrin-based supramolecular systems for drug delivery: Recent progress and future perspective. Adv. Drug Deliv. Rev. 2013, 65, 1215-1233. [CrossRef] [PubMed]

7. Sherje, A.P.; Dravyakar, B.R.; Kadam, D.; Jadhav, M. Cyclodextrin-based nanosponges: A critical review. Carbohydr. Polym. 2017, 173, 37-49. [CrossRef] 
8. Crini, G.; Fourmentin, S.; Fenyvesi, É.; Torri, G.; Fourmentin, M.; Morin-Crini, N. Cyclodextrins, from molecules to applications. Environ. Chem. Lett. 2018, 16, 1361-1375. [CrossRef]

9. Singh, P.; Ren, X.; Guo, T.; Wu, L.; Shakya, S.; He, Y.; Wang, C.; Maharjan, A.; Singh, V.; Zhang, J. Biofunctionalization of $\beta$-cyclodextrin nanosponges using cholesterol. Carbohydr. Polym. 2018, 190, 23-30. [CrossRef]

10. Caldera, F.; Tannous, M.; Cavalli, R.; Zanetti, M.; Trotta, F. Evolution of cyclodextrin nanosponges. Int. J. Pharm. 2017, 531, 470-479. [CrossRef]

11. Chilajwar, S.V.; Pednekar, P.P.; Jadhav, K.R.; Gupta, G.J.C.; Kadam, V.J. Cyclodextrin-based nanosponges: A propitious platform for enhancing drug delivery. Expert Opin. Drug Deliv. 2014, 11, 111-120. [CrossRef] [PubMed]

12. Trotta, F.; Cavalli, R. Characterization and applications of new hyper-cross-linked cyclodextrins. Compos. Interfaces 2009, 16, 39-48. [CrossRef]

13. Alongi, J.; Pošsković, M.; Frache, A.; Trotta, F. Novel flame retardants containing cyclodextrin nanosponges and phosphorus compounds to enhance EVA combustion properties. Polym. Degrad. Stab. 2010, 95, 2093-2100. [CrossRef]

14. Ansari, K.A.; Torne, S.J.; Vavia, P.P.R.; Trotta, F.; Cavalli, R. Paclitaxel loaded nanosponges: In-vitro characterization and cytotoxicity study on MCF-7 cell line culture. Curr. Drug Deliv. 2011, 8, 194-202. [CrossRef]

15. Gigliotti, C.L.; Minelli, R.; Cavalli, R.; Occhipinti, S.; Barrera, G.; Pizzimenti, S.; Cappellano, G.; Boggio, E.; Conti, L.; Fantozzi, R.; et al. In vitro and in vivo therapeutic evaluation of camptothecin-encapsulated $\beta$-cyclodextrin nanosponges in prostate cancer. $J$. Biomed. Nanotechnol. 2016, 12, 114-127. [CrossRef] [PubMed]

16. Swaminathan, S.; Cavalli, R.; Trotta, F. Cyclodextrin-based nanosponges: A versatile platform for cancer nanotherapeutics development. Wiley Interdiscip. Rev. Nanomed. Nanobiotechnol. 2016, 8, 579-601. [CrossRef] [PubMed]

17. Swaminathan, S.; Pastero, L.; Serpe, L.; Trotta, F.; Vavia, P.; Aquilano, D.; Trotta, M.; Zara, G.P.; Cavalli, R. Cyclodextrin-based nanosponges encapsulating camptothecin: Physicochemical characterization, stability and cytotoxicity. Eur. J. Pharm. Biopharm. 2010, 74, 193-201. [CrossRef]

18. Venuti, V.; Rossi, B.; Mele, A.; Melone, L.; Punta, C.; Majolino, D.; Masciovecchio, C.; Caldera, F.; Trotta, F. Tuning structural parameters for the optimization of drug delivery performance of cyclodextrin-based nanosponges. Expert Opin. Drug Deliv. 2017, 14, 331-340. [CrossRef]

19. Seglie, L.; Martina, K.; Devecchi, M.; Roggero, C.; Trotta, F.; Scariot, V. The effects of 1-MCP in cyclodextrin-based nanosponges to improve the vase life of Dianthus caryophyllus cut flowers. Postharvest Biol. Technol. 2011, 59, 200-205. [CrossRef]

20. Irsfeld, M.; Spadafore, M.; Prüß, B.M. $\beta$-phenylethylamine, a small molecule with a large impact. Webmedcentral 2013, 4, 4409.

21. Szabo, A.; Billett, E.; Turner, J. Phenylethylamine, a possible link to the antidepressant effects of exercise? Br. J. Sports Med. 2001, 35, 342-343. [CrossRef]

22. Venkatachalam, T.K.; Sudbeck, E.A.; Mao, C.; Uckun, F.M. Anti-HIV activity of aromatic and heterocyclic Thiazolyl Thiourea compounds. Bioorg. Med. Chem. Lett. 2001, 11, 523-528. [CrossRef]

23. Holla, B.S.; Malini, K.V.; Rao, B.S.; Sarojini, B.K.; Kumari, N.S. Synthesis of some new 2,4-disubstituted thiazoles as possible antibacterial and anti-inflammatory agents. Eur. J. Med. Chem. 2003, 38, 313-318. [CrossRef]

24. Das, J.; Chen, P.; Norris, D.; Padmanabha, R.; Lin, J.; Moquin, R.V.; Shen, Z.; Cook, L.S.; Doweyko, A.M.; Pitt, S.; et al. 2-Aminothiazole as a novel kinase inhibitor template. Structure-activity relationship studies toward the discovery of N-(2-chloro6-methylphenyl)-2-[[6-[4-(2-hydroxyethyl)-1-piperazinyl]-2-methyl-4-pyrimidinyl]amino]-1,3-thiazole-5-carboxamide (dasatinib, BMS-354825) as a potent pan-Src kinase inhibitor. J. Med. Chem. 2006, 49, 6819-6832. [CrossRef] [PubMed]

25. Sierpe, R.; Lang, E.; Jara, P.; Guerrero, A.R.; Chornik, B.; Kogan, M.J.; Yutronic, N. Gold nanoparticles interacting with $\beta$ cyclodextrin-phenylethylamine inclusion complex: A ternary system for photothermal drug release. ACS Appl. Mater. Interfaces 2015, 7, 22-31. [CrossRef]

26. Asela, I.; Noyong, M.; Simon, U.; Andrades-Lagos, J.; Campanini-Salinas, J.; Vásquez-Velásquez, D.; Kogan, M.; Yutronic, N.; Sierpe, R. Gold nanoparticles stabilized with $\beta$ cyclodextrin-2-amino-4-(4-chlorophenyl) thiazole complex: A novel system for drug transport. PLoS ONE 2017, 12, e0185652. [CrossRef]

27. Yeh, Y.C.; Creran, B.; Rotello, V.M. Gold nanoparticles: Preparation, properties, and applications in bionanotechnology. Nanoscale 2012, 4, 1871-1880. [CrossRef]

28. Elahi, N.; Kamali, M.; Baghersad, M.H. Recent biomedical applications of gold nanoparticles: A review. Talanta 2018, 184, 537-556. [CrossRef] [PubMed]

29. Zhang, Y.; Qian, J.; Wang, D.; Wang, Y.; He, S. Multifunctional gold nanorods with ultrahigh stability and tunability for in vivo fluorescence imaging, SERS detection, and photodynamic therapy. Angewandte Chemie 2013, 52, 1148-1151. [CrossRef]

30. Shi, J.; Votruba, A.R.; Farokhzad, O.C.; Langer, R. Nanotechnology in drug delivery and tissue engineering: From discovery to applications. Nano Lett. 2010, 10, 3223-3230. [CrossRef]

31. Guo, J.; Rahme, K.; He, Y.; Li, L.L.; Holmes, J.D.; O’Driscoll, C.M. Gold nanoparticles enlighten the future of cancer theranostics. Int. J. Nanomed. 2017, 12, 6131-6152. [CrossRef]

32. Murphy, C.J.; Gole, A.M.; Stone, J.W.; Sisco, P.N.; Alkilany, A.M.; Goldsmith, E.C.; Baxter, S.C. Gold nanoparticles in biology: Beyond toxicity to cellular imaging. Acc. Chem. Res. 2008, 41, 1721-1730. [CrossRef]

33. Saha, K.; Agasti, S.S.; Kim, C.; Li, X.; Rotello, V.M. Gold nanoparticles in chemical and biological sensing. Chem. Rev. 2012, 112, 2739-2779. [CrossRef] 
34. Duncan, B.; Kim, C.; Rotello, V.M. Gold nanoparticle platforms as drug and biomacromolecule delivery systems. J. Control. Release 2010, 148, 122-127. [CrossRef] [PubMed]

35. Tapia-Arellano, A.; Gallardo-Toledo, E.; Ortiz, C.; Henríquez, J.; Feijóo, C.G.; Araya, E.; Sierpe, R.; Kogan, M.J. Functionalization with PEG/Angiopep-2 peptide to improve the delivery of gold nanoprisms to central nervous system: In vitro and in vivo studies. Mater. Sci. Eng. C 2021, 121, 111785. [CrossRef]

36. Gao, N.; Sun, H.; Dong, K.; Ren, J.; Qu, X. Gold-nanoparticle-based multifunctional amyloid- $\beta$ inhibitor against Alzheimer's disease. Chem. A Eur. J. 2015, 21, 829-835. [CrossRef] [PubMed]

37. Hainfeld, J.F.; Smilowitz, H.M.; O'Connor, M.J.; Dilmanian, F.A.; Slatkin, D.N. Gold nanoparticle imaging and radiotherapy of brain tumors in mice. Nanomedicine 2013, 8, 1601-1609. [CrossRef] [PubMed]

38. Riley, R.S.; Day, E.S. Gold nanoparticle-mediated photothermal therapy: Applications and opportunities for multimodal cancer treatment. Wiley Interdiscip. Rev. Nanomed. Nanobiotechnol. 2017, 9. [CrossRef] [PubMed]

39. Morales-Zavala, F.; Arriagada, H.; Hassan, N.; Velasco, C.; Riveros, A.; Álvarez, A.R.; Minniti, A.N.; Rojas-Silva, X.; Muñoz, L.L.; Vasquez, R.; et al. Peptide multifunctionalized gold nanorods decrease toxicity of $\beta$-amyloid peptide in a Caenorhabditis elegans model of Alzheimer's disease. Nanomed. Nanotechnol. Biol. Med. 2017, 13, 2341-2350. [CrossRef] [PubMed]

40. Hassan, N.; Cordero, M.L.; Sierpe, R.; Almada, M.; Juárez, J.; Valdez, M.; Riveros, A.; Vargas, E.; Abou-Hassan, A.; Ruso, J.M.; et al. Peptide functionalized magneto-plasmonic nanoparticles obtained by microfluidics for inhibition of $\beta$-amyloid aggregation. J. Mater. Chem. B 2018, 6, 5091-5099. [CrossRef]

41. Guerrero, A.R.; Hassan, N.; Escobar, C.A.; Albericio, F.; Kogan, M.J.; Araya, E. Gold nanoparticles for photothermally controlled drug release. Nanomedicine 2014, 9, 2023-2039. [CrossRef] [PubMed]

42. Wust, P.; Hildebrandt, B.; Sreenivasa, G.; Rau, B.; Gellermann, J.; Riess, H.; Felix, R.; Schlag, P. Hyperthermia in combined treatment of cancer. Lancet Oncol. 2002, 3, 487-497. [CrossRef]

43. Liu, Y.; Sun, D.; Fan, Q.; Ma, Q.; Dong, Z.; Tao, W.; Tao, H.; Liu, Z.; Wang, C. The enhanced permeability and retention effect based nanomedicine at the site of injury. Nano Res. 2020, 13, 564-569. [CrossRef]

44. Jain, S.; Hirst, D.G.; O'Sullivan, J.M. Gold nanoparticles as novel agents for cancer therapy. Br. J. Radiol. 2012, 85, 101-113. [CrossRef]

45. Maeda, H. The enhanced permeability and retention (EPR) effect in tumor vasculature: The key role of tumor-selective macromolecular drug targeting. Adv. Enzyme Regul. 2001, 41, 189-207. [CrossRef]

46. Madan, J.; Dhiman, N.; Sardana, S.; Aneja, R.; Chandra, R.; Katyal, A. Long-circulating poly(ethylene glycol)-grafted gelatin nanoparticles customized for intracellular delivery of noscapine: Preparation, in-vitro characterization, structure elucidation, pharmacokinetics, and cytotoxicity analyses. Anticancer Drugs 2011, 19, 1061-1067. [CrossRef]

47. Silva, N.; Riveros, A.; Yutronic, N.; Lang, E.; Chornik, B.; Guerrero, S.; Samitier, J.; Jara, P.; Kogan, M. Photothermally controlled methotrexate release system using $\beta$-cyclodextrin and gold nanoparticles. Nanomaterials 2018, 8, 985. [CrossRef] [PubMed]

48. Xue, Q.; Liu, Z.; Guo, Y.; Guo, S. Cyclodextrin functionalized graphene-gold nanoparticle hybrids with strong supramolecular capability for electrochemical thrombin aptasensor. Biosens. Bioelectron. 2015, 68, 429-436. [CrossRef]

49. Park, C.; Youn, H.; Kim, H.; Noh, T.; Kook, Y.H.; Oh, E.T.; Park, H.J.; Kim, C. Cyclodextrin-covered gold nanoparticles for targeted delivery of an anti-cancer drug. J. Mater. Chem. 2009, 19, 2310-2315. [CrossRef]

50. Barlas, F.B.; Aydindogan, E.; Arslan, M.; Timur, S.; Yagci, Y. Gold nanoparticle conjugated poly(p-phenylene- $\beta$-cyclodextrin)graft-poly(ethylene glycol) for theranostic applications. J. Appl. Polym. Sci. 2019, 136, 47250. [CrossRef]

51. Wang, H.; Chen, Y.; Li, X.Y.; Liu, Y. Synthesis of oligo(ethylenediamino)- $\beta$-cyclodextrin modified gold nanoparticle as a DNA concentrator. Mol. Pharm. 2007, 4, 189-198. [CrossRef] [PubMed]

52. Liu, Y.; Zhao, Y.L.; Chen, Y.; Wang, M. Supramolecular assembly of gold nanoparticles mediated by polypseudorotaxane with thiolated $\beta$-cyclodextrin. Macromol. Rapid Commun. 2005, 26, 401-406. [CrossRef]

53. Donoso-González, O.; Lodeiro, L.; Aliaga, Á.E.; Laguna-Bercero, M.A.; Bollo, S.; Kogan, M.J.; Yutronic, N.; Sierpe, R. Functionalization of gold nanostars with cationic $\beta$-cyclodextrin-based polymer for drug co-loading and SERS monitoring. Pharmaceutics 2021, 13, 261. [CrossRef]

54. Patel, P.; Deshpande, A. Patent review on cyclodextrin based nanosponges prepared by different methods: Physicochemical characterization, factors influencing formation and applications. World J. Pharm. Sci. 2014, 2, 380-385.

55. Coleman, A.W.; Nicolis, I.; Keller, N.; Dalbiez, J.P. Aggregation of cyclodextrins: An explanation of the abnormal solubility of $\beta$-cyclodextrin. J. Incl. Phenom. Mol. Recognit. Chem. 1992, 13, 139-143. [CrossRef]

56. Rita, L.; Amit, T.; Chandrashekhar, G. Current trends in B-cyclodextrin based drug delivery systems. Int. J. Res. Ayurveda Pharm. 2011, 2, 1520-1526.

57. Bolmal, U.B.; Manvi, F.V.; Kotha, R.; Palla, S.S.; Paladugu, A.; Reddy, K.R. Recent advances in nanosponges as drug delivery system. Int. J. Pharm. Sci. Nanotechnol. 2013, 6, 1934-1944. [CrossRef]

58. Omar, S.M.; Ibrahim, F.; Ismail, A. Formulation and evaluation of cyclodextrin-based nanosponges of griseofulvin as pediatric oral liquid dosage form for enhancing bioavailability and masking bitter taste. Saudi Pharm. J. 2020, 28, 349-361. [CrossRef] [PubMed]

59. Higuchi, T.; Connors, K.A. Phase solubility techniques. In Advances in Analytical Chemistry and Instrumentation; Wiley-Interscience: New York, NY, USA, 1965; Volume 4, pp. 117-212. 
60. Turkevich, J.; Stevenson, P.C.; Hillier, J. A study of the nucleation and growth processes in the synthesis of colloidal gold. Discuss. Faraday Soc. 1951, 11, 55-75. [CrossRef]

61. Liu, X.; Atwater, M.; Wang, J.; Huo, Q. Extinction coefficient of gold nanoparticles with different sizes and different capping ligands. Colloids Surf. B Biointerfaces 2007, 58, 3-7. [CrossRef]

62. Near, R.D.; Hayden, S.C.; Hunter, R.E.; Thackston, D.; El-Sayed, M.A. Rapid and efficient prediction of optical extinction coefficients for gold nanospheres and gold nanorods. J. Phys. Chem. C 2013, 117, 23950-23955. [CrossRef]

63. Darandale, S.S.; Vavia, P.R. Cyclodextrin-based nanosponges of curcumin: Formulation and physicochemical characterization. J. Incl. Phenom. Macrocycl. Chem. 2013, 75, 315-322. [CrossRef]

64. Sambasevam, K.P.; Mohamad, S.; Sarih, N.M.; Ismail, N.A. Synthesis and characterization of the inclusion complex of $\beta$ cyclodextrin and azomethine. Int. J. Mol. Sci. 2013, 14, 3671-3682. [CrossRef]

65. Yaşayan, G.; Şatıroğlu Sert, B.; Tatar, E.; Küçükgüzel, İ. Fabrication and characterisation studies of cyclodextrin-based nanosponges for sulfamethoxazole delivery. J. Incl. Phenom. Macrocycl. Chem. 2020, 97, 175-186. [CrossRef]

66. Dobkowski, Z. Thermal analysis techniques for characterization of polymer materials. Polym. Degrad. Stab. 2006, 91, 488-493. [CrossRef]

67. Trotta, F.; Zanetti, M.; Camino, G. Thermal degradation of cyclodextrins. Polym. Degrad. Stab. 2000, 69, 373-379. [CrossRef]

68. Jiang, H.L.; Lin, J.C.; Hai, W.; Tan, H.W.; Luo, Y.W.; Xie, X.L.; Cao, Y.; He, F.A. A novel crosslinked $\beta$-cyclodextrin-based polymer for removing methylene blue from water with high efficiency. Colloids Surf. A Physicochem. Eng. Asp. 2019, 560, 59-68. [CrossRef]

69. Matencio, A.; Dhakar, N.K.; Bessone, F.; Musso, G.; Cavalli, R.; Dianzani, C.; García-Carmona, F.; López-Nicolás, J.M.; Trotta, F. Study of oxyresveratrol complexes with insoluble cyclodextrin based nanosponges: Developing a novel way to obtain their complexation constants and application in an anticancer study. Carbohydr. Polym. 2020, 231, 115763. [CrossRef] [PubMed]

70. Han, L.; Ma, G.; Xie, S.; Sun, J.; Jia, Y.; Jing, Y. Thermal properties and stabilities of the eutectic mixture: 1,6-hexanediol/lauric acid as a phase change material for thermal energy storage. Appl. Therm. Eng. 2017, 116, 153-159. [CrossRef]

71. Herrera, B.A.; Bruna, T.C.; Sierpe, R.A.; Lang, E.P.; Urzúa, M.; Flores, M.I.; Jara, P.S.; Yutronic, N.I. A surface functionalized with per-(6-amino-6-deoxy)- $\beta$-cyclodextrin for potential organic pollutant removal from water. Carbohydr. Polym. 2020, $233,115865$. [CrossRef]

72. Rao, V.M.; Stella, V.J. When can cyclodextrins be considered for solubilization purposes? J. Pharm. Sci. 2003, 92, 927-932. [CrossRef] [PubMed]

73. Connors, K.A. The stability of cyclodextrin complexes in solution. Chem. Rev. 1997, 97, 1325-1358. [CrossRef]

74. Sierpe, R.; Noyong, M.; Simon, U.; Aguayo, D.; Huerta, J.; Kogan, M.J.; Yutronic, N. Construction of 6-thioguanine and 6mercaptopurine carriers based on $\beta$ cyclodextrins and gold nanoparticles. Carbohydr. Polym. 2017, 177, 22-31. [CrossRef] [PubMed]

75. Kim, H.S.; Lee, D.Y. Photothermal therapy with gold nanoparticles as an anticancer medication. J. Pharm. Investig. 2017, 47, 19-26. [CrossRef]

76. Tao, Y.; Chan, H.F.; Shi, B.; Li, M.; Leong, K.W. Light: A magical tool for controlled drug delivery. Adv. Funct. Mater. 2020, 30, 2005029. [CrossRef]

77. Yen, H.J.; Hsu, S.H.; Tsai, C.L. Cytotoxicity and immunological response of gold and silver nanoparticles of different sizes. Small 2009, 5, 1553-1561. [CrossRef] 